City University of New York (CUNY) CUNY Academic Works

2014

\title{
Analyzing the Influence of Micro-Level Factors on CCTV Camera Effect.
}

Eric L. Piza

CUNY John Jay College

Joel M. Caplan

Rutgers University

Leslie W. Kennedy

Rutgers University

\section{How does access to this work benefit you? Let us know!}

More information about this work at: https://academicworks.cuny.edu/jj_pubs/176

Discover additional works at: https://academicworks.cuny.edu

This work is made publicly available by the City University of New York (CUNY).

Contact: AcademicWorks@cuny.edu 


\title{
Analyzing the Influence of Micro-Level Factors on CCTV Camera Effect
}

\author{
Eric L. Piza • Joel M. Caplan • Leslie W. Kennedy
}

Published online: 31 May 2013

(C) Springer Science+Business Media New York 2013

\begin{abstract}
Objectives Despite the popularity of closed circuit television (CCTV), evidence of its crime prevention capabilities is inconclusive. Research has largely reported CCTV effect as "mixed" without explaining this variance. The current study contributes to the literature by testing the influence of several micro-level factors on changes in crime levels within CCTV areas of Newark, NJ.

Methods Viewsheds, denoting the line-of-sight of CCTV cameras, were units of analysis $(\mathrm{N}=117)$. Location quotients, controlling for viewshed size and control-area crime incidence, measured changes in the levels of six crime categories, from the pre-installation period to the post-installation period. Ordinary least squares regression models tested the influence of specific micro-level factors-environmental features, camera line-of-sight, enforcement activity, and camera design — on each crime category.

Results First, the influence of environmental features differed across crime categories, with specific environs being related to the reduction of certain crimes and the increase of others. Second, CCTV-generated enforcement was related to the reduction of overall crime, violent crime and theft-from-auto. Third, obstructions to CCTV line-of-sight caused by immovable objects were related to increased levels of auto theft and decreased levels of violent crime, theft from auto and robbery.

Conclusions The findings suggest that CCTV operations should be designed in a manner that heightens their deterrent effect. Specifically, police should account for the presence of crime generators/attractors and ground-level obstructions when selecting camera sites, and design the operational strategy in a manner that generates maximum levels of enforcement.
\end{abstract}

Keywords CCTV · Viewsheds · Crime-and-place - GIS · OLS regression · Newark, NJ

\footnotetext{
E. L. Piza $(\bowtie)$

Department of Law and Police Science, John Jay College of Criminal Justice,

New York, NY, USA

e-mail: eric.piza@gmail.com

J. M. Caplan · L. W. Kennedy

School of Criminal Justice, Rutgers University, Newark, NJ, USA
} 


\section{Introduction}

The popularity of closed circuit television (CCTV) has grown exponentially in recent times. The tactic's rise can be traced to Great Britain, where three quarters of the Home Office budget funded CCTV-related projects from 1996 to 1998 (Armitage 2002). This generated a dramatic expansion of CCTV in Britain, from approximately one hundred systems in 1990 (Armitage 2002) to over four million less than two decades later (Farrington et al. 2007). The deployment of CCTV in numerous American cities suggests that the United States has begun to follow a similar path (Cameron et al. 2008; Caplan et al. 2011; King et al. 2008; La Vigne et al. 2011; Mazerolle et al. 2002; Ratcliffe et al. 2009).

Despite this worldwide popularity, best-practices for CCTV in policing have been largely understudied. Specifically, little effort has been devoted to understanding how CCTV effect can be maximized. CCTV systems often have a vague mission to "prevent crime" with little consideration being given to a number of pertinent issues, such as site selection, proactive monitoring practices, evidence collection, and training (Gill and Spriggs 2005).

This study moves beyond the typical research question of "Does CCTV work?" towards "In which context does CCTV work best?" We test the influence of several micro-level factors on changes in post-installation crime levels within camera viewsheds. The methodology builds upon previous research suggesting the heterogeneity of pertinent characteristics of camera sites may explain the varying effect of CCTV (Caplan et al. 2011; Ratcliffe et al. 2009). Our findings suggest that CCTV effect is contextual, somewhat influenced by a camera's environmental backcloth, line-of-sight, ability to generate proactive enforcement, and the targeted crime type.

\section{Review of Relevant Literature}

The "Mixed" Effect of CCTV and the Influence of Methodology

Reaching a firm consensus on the crime prevention capacity of CCTV is somewhat difficult. While numerous evaluations have reported some positive outcomes (Caplan et al. 2011; La Vigne et al. 2011; Mazerolle et al. 2002; Ratcliffe et al. 2009), CCTV has not produced consistent benefits and, in many instances, there has been little or no evidence of crime reductions (Cameron et al. 2008; Farrington et al. 2007; Gill and Spriggs 2005; King et al. 2008). Given these findings, it is difficult to anticipate the performance of CCTV upon installation. While previous works have called for the identification of precise contexts in which CCTV best performs (Caplan et al. 2011; Gill and Spriggs 2005; Phillips 1999; Ratcliffe et al. 2009; Welsh and Farrington 2002) little has been developed in the sense of "best practices." While inconsistent findings may be due to differences in the utility of individual operations (La Vigne et al. 2011) or characteristics of target areas (Eck 2002), limitations of common research methodologies may have also contributed to the uncertainty (Caplan et al. 2011).

A particular methodological issue revolves around the scope of most CCTV studies. The vast majority of CCTV evaluations measure impact on a macro level; systems considered as a whole are deemed as either effective or ineffective at preventing crime (King et al., 2008; Mazerolle et al., 2002; Phillips, 1999; Welsh and Farrington, 2007, 2009). While the analysis of entire systems is obviously a necessary endeavor, this approach precludes the exploration of CCTV's micro-level effect. Such research essentially dismisses the possibility that effective camera sites exist within ineffective systems, and vice versa (Caplan et al. 2011: 270). 
The aggregation of findings is largely a function of the requirement to accommodate the units of analysis employed in CCTV research. Researchers have typically utilized aggregate geographies where cameras were installed, such as "neighborhoods" or "police districts," in tests of CCTV (Brown 1995; Ditton and Short 1999; Sivarajasingam et al. 2003; Squires 2000). Measuring crime at such large units precludes researchers from disaggregating data to test intervention effects within micro-areas (Johnson et al. 2009: 172). Aggregate geographies also suffer from the fact that they constitute poor representations of camera coverage. As publiclydeployed cameras have the ability to view limited distances, areas such as "neighborhoods" vastly overestimate CCTV coverage. In addition, pre-determined administrative boundaries may not be fit for social analysis for the simple_-yet commonly overlooked—fact that they are more often drawn for the convenience of service delivery and are not necessarily representative of the behavioral clusters that are of interest for surveillance. It is unlikely that people cognitively recognize such boundaries, let alone base their travel patterns on these units.

Another common approach is the designation of circular buffer areas around cameras as units of analysis (Cameron et al. 2008; La Vigne et al. 2011; Mazerolle et al. 2002). While buffer zones truncate the size of targets areas, they also can inaccurately reflect CCTV coverage. Buffer zones assume a 360 degree, unobstructed line-of-sight for each camera, which rarely occurs in a real world environment (Chainey 2000; Eck 2002). Street signs, building awnings, and telephone poles are common fixtures that can restrict a camera's line-of-sight. Therefore, the geography depicted by a circular buffer does not realistically depict a camera's coverage area.

Recent CCTV evaluations by Caplan et al. (2011) and Ratcliffe et al. (2009) improve upon traditional CCTV methodologies. Both of these studies utilized viewsheds denoting the actual line-of-sight of cameras as units of analysis. ${ }^{1}$ Caplan et al. (2011) utilized a method that estimated each camera's viewshed via aerial imagery of CCTV areas in Newark, NJ. The researchers created 582-foot buffers around each camera location (representing twice the median length of Newark's blocks), then used ArcGIS tools to digitize viewshed polygons that accounted for buildings and other barriers to a camera's line of sight. Ratcliffe et al. (2009) took a more hands-on, albeit less accessible, approach in their evaluation of Philadelphia's CCTV system by viewing actual camera feeds at the police department. In conjunction with police personnel, the researchers digitized precise areas visible to each camera. Viewsheds more accurately reflect camera coverage than traditionally utilized units of analysis while recognizing each camera site as a unique environment. Such an approach allows researchers to test the intrasystem effect of CCTV in addition to overall system performance. Indeed, Ratcliffe et al. (2009) found that while Philadelphia's CCTV system generated a $13.3 \%$ reduction in overall crime,

\footnotetext{
${ }^{1}$ Under the deterrence doctrine, CCTV is most likely to prevent crime when an offender believes cameras may be monitoring their activity and perceives this attention to put them at increased risk of apprehension. This has implications regarding the units of analysis utilized in CCTV research. As articulated by Ratcliffe et al. (2009), "the difficulty with offender perceptions is that they are not measurable without extensive and expensive interviewing. Furthermore, the resultant offender perception will most likely vary from person to person. In other words, while the range of a CCTV camera-as perceived by a criminal-is in the eye of the beholder, finding and interviewing suitable beholders is beyond the budget of most studies, and the results are likely to be quite variable" (751). However, while Ratcliffe et al. presented viewsheds as an alternative to the "offender perception" approach, the concepts certainly overlap. Deterrence can only be realistically expected where a potential offender's conception of "space" and a CCTV camera's line-of-sight coincide. In this sense, a camera's surrounding environment comprises a "spatial node" cogitatively identified by pedestrians as a singular "place" (Lynch 1960). It is within such an area an offender would most likely perceive a heightened level of risk. Given the limited visual extent of cameras, the area immediately visible to CCTV is probably the geography in which offender perception of camera presence is at its peak. Furthermore, viewsheds likely more accurately reflect street-level perceptions of potential offenders than the types of units of analysis traditionally utilized in CCTV research (e.g. "neighborhoods" and "buffers").
} 
just as many individual cameras had no effect on crime as there were locations that showed a benefit. Caplan et al. (2011) reported a similar pattern in Newark, NJ. While auto theft was the only crime to experience a system-wide reduction, of the 73 cameras in place at the time 58 experienced reduced levels of shootings, 34 experienced reduced levels of auto theft and 41 experienced reduced levels of theft from auto.

\section{Towards Explaining the Varying Effect of CCTV}

The findings of Caplan et al. (2011) and Ratcliffe et al. (2009) have significant implications for CCTV policy and practice. The varied effect of individual cameras within singular systems suggests cameras may have differed on certain factors that influence effectiveness. Police may be able to maximize CCTV effect by identifying and strategically manipulating such factors. Findings of previous research suggest a number of CCTV characteristics whose heterogeneity across camera sites may help explain variance in effectiveness.

CCTV effect may be related to specific place-based characteristics of target areas. Just as certain crimes are conducive to certain environments, specific crime prevention tactics (e.g. CCTV) may be more effective at certain places than others (Eck 2002). Despite the rich literature demonstrating the effect of the environment on crime incidence (Brantingham and Brantingham 1993; Eck and Weisburd 1995; Groff and La Vigne 2001; Kennedy et al. 2011), the environmental composition of CCTV areas has been largely ignored. A noteworthy exception is the recent meta-analysis conducted by Welsh and Farrington (2009). Forty-four studies were categorized according to one of four main settings: city and town centers, public housing, public transport, and car parks. Car park systems produced the largest crime reductions, which concurs with findings of nationallevel studies in the UK (Gill and Spriggs 2005; Farrington et al. 2007).

Despite this observed support for CCTV in car parks, the results are not without caveats. The findings are complicated by the fact that each of the six car park evaluations included in CCTV meta-analyses and multi-site evaluations (Farrington et al. 2007; Gill and Spriggs 2005; Welsh and Farrington 2009) were combined with other interventions, namely improved lighting, improved fencing, and security guards. Thus, crime reductions in car parks may speak more to the effectiveness of a package of interventions focused on a particular crime type (e.g. "car crime") than the specific effect of CCTV (Welsh and Farrington 2007: 46). In addition, aggregate classifications of study settings may fail to capture the unique characteristics of each camera's surrounding environment. Grouping all "city center" systems together, for example, ignores micro-level features that can differ across sites. It is certainly possible that a particular city center may be rife with crime generators/attractors while others are relatively free of them. In this sense, Oberwittler and Wikström (2009) argue smaller units of analysis are less likely to be heterogeneous in their environmental composition than larger areas. Thus, environmental context is better measured through Brantingham and Brantingham's (1993: 6) concept of the "environmental backcloth," defined as "elements that surround and are part of an individual and that may be influenced by or influence his or her criminal behavior," than larger areas.

Previous studies have found high levels of camera coverage to be particularly associated with successful CCTV deployment. The percentage of target areas covered by CCTV (Farrington et al. 2007) and number of cameras installed per unit area (Gill and Spriggs 2005) have shown to be related to crime reduction. Camera design may also be influential. Public CCTV cameras primarily take one of two forms: traditionally-designed overt cameras and semi-covert "dome" cameras that employ one-way transparent casing (Ratcliffe 2006: 4-5). As illustrated in Fig. 1, the line of sight of overt cameras is easily determined while semi-covert "dome" cameras do not reveal the exact places and/or 

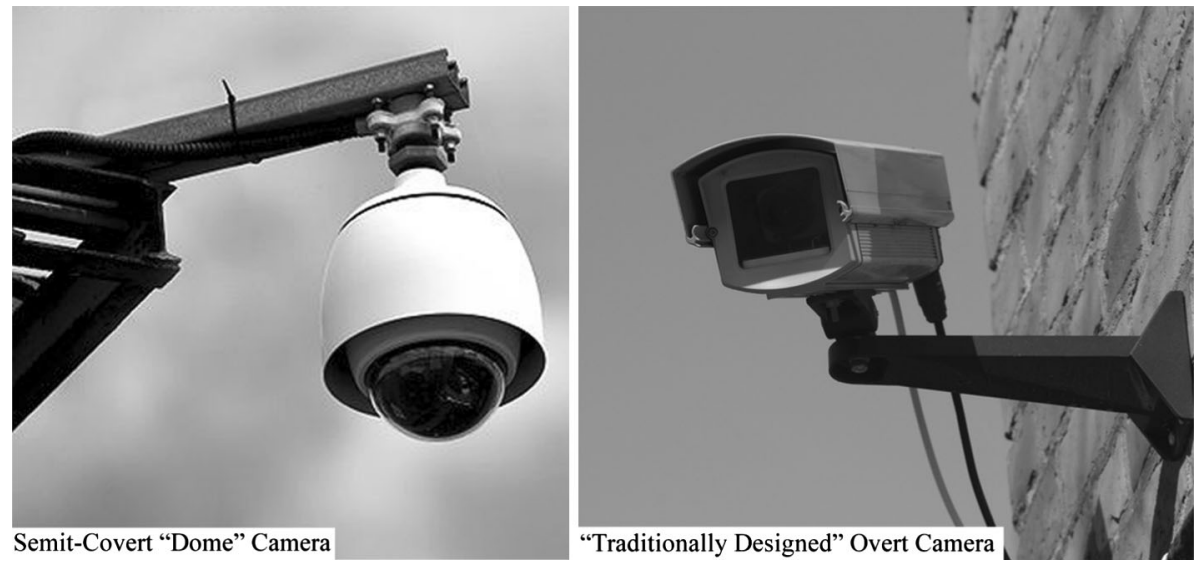

Fig. 1 Semi-covert and overt CCTV cameras

persons currently under surveillance. Caplan et al. (2011) argued that the opaque housing of dome cameras make them more likely "to produce a sense of omnipresence monitoring of the viewshed at all times" as compared to traditionally designed cameras (261). While proponents of overt systems claim conspicuous camera presence produces deterrence, riskappraisal by potential offenders may be facilitated by such systems. Waples and Gill (2006: 12), for example, found that "box cameras" whose line-of-sight was easily determined afforded offenders the opportunity to avoid detection by offending "behind the camera's back." Such observations suggest that cameras allowing for the easy identification of precise places under surveillance may have a diminished capacity to generate deterrence as compared to semi-covert "dome" cameras.

Finally, the varying effect of CCTV may be related to the level to which the technology is incorporated into routine law enforcement tactics. The importance of such integration is strongly supported by recent research of the Urban Institute (La Vigne et al. 2011). La Vigne et al. (2011) analyzed CCTV systems in three US cities: Baltimore, Chicago, and Washington, DC. The systems that effectively reduced crime were those most frequently monitored by police and heavily incorporated into the police function. In Baltimore, police integrated the camera system into the daily routine of proactive street units and designed patrols to add additional coverage to areas officials felt would be susceptible to crime displacement. The researchers found that three of the four Baltimore systems experienced crime decreases. In Chicago, police generated surveillance "missions," which designated specific camera sites to receive enhanced levels of monitoring on a daily basis. One of Chicago's systems experienced a significant decrease in total crime counts with the other experiencing a significant decline in robbery. Washington DC, on the other hand, rarely incorporated active monitoring operations and experienced no tangible crime control benefits as a result of CCTV. The findings of La Vigne et al. (2011) are further supported by other research finding CCTV systems incorporating no active monitoring have little effect on crime (King et al. 2008; La Vigne and Lowry 2011).

\section{Literature Review Summary and Scope of the Current Study}

Research on CCTV has thus far generated little in the sense of "transferrable lessons" (Gill and Spriggs 2005). While most evaluations find the crime prevention utility of CCTV to be 
"mixed," limitations of common research designs do not allow for exploration of this variability. Units of analysis often fail to incorporate micro-level geographies appropriate in the study of place-based crime prevention efforts (Weisburd et al. 2008). Furthermore, data on the heterogeneity of pertinent CCTV-related factors are often not accessible to researchers.

The current study picks up where Caplan et al. (2011) left off in their study of CCTV in Newark, while building upon the viewshed methodology of Ratcliffe et al. (2009). Our particular aim is the identification of micro-level factors influencing CCTV camera effectiveness. Crime level changes were calculated for each individual camera site, allowing for an intra-system observation of effect heterogeneity. Statistical models controlling for the presence of certain crime attractors and generators, camera line-of-sight, enforcement activity, and camera design allowed us to test the influence of numerous factors on CCTV camera effect.

\section{Research Setting}

Newark is the largest city in New Jersey, spanning approximately twenty-six square miles with a population of nearly 280,000 persons (US Census Bureau 2011). In 2006, under new leadership, the Newark Police Department underwent a major re-organization and change in mission, and simultaneously upgraded many of their technological capabilities. Technology investments included a public CCTV system, which currently includes 146 cameras. Most cameras are installed on the street-level $(\mathrm{N}=137)$ compared to rooftops $(\mathrm{N}=9)$ with the design being split between semi-covert "dome" cameras $(\mathrm{N}=114)$ and traditionally-designed overt cameras $(\mathrm{N}=32)$. Live footage from the cameras is monitored from a centralized control room at the police department by two CCTV operators under the supervision of a police sergeant.

Despite the emphasis on live monitoring, levels of detections are low in Newark, which concurs with findings of previous research (Ditton and Short 1999; Gill et al. 2005; Norris and Armstrong 1999; Norris and McCahill 2006; Sarno et al. 1999). Figure 2 shows the detection frequency of viewsheds during the 1-year study period. While viewsheds averaged 6.30 detections, 21 viewsheds $(17.9 \%)$ generated no detections and $86(73.5 \%)$ generated five detections or less. Enforcement activity was even more infrequent. Viewsheds averaged 1.91 enforcement actions, with $65(55.5 \%)$ generating none, and 168 $(92.3 \%)$ generating five or less. The infrequent nature of proactive surveillance is also reflected by the system-wide statistics. While the system generated 26.84 detections and 9.47 enforcement actions per week at the onset of the operation, activity reduced to weekly averages of 2.11 detections and 1.22 enforcement actions when the system expanded to 146 cameras (Piza et al. 2012: 19).

The impact of Newark's CCTV system on crime has received little empirical attention outside of the aforementioned analysis by Caplan et al. (2011), which found auto theft to be the only one of the three crime types included in the analysis to have experienced a systemwide reduction. In addition to measuring the system-wide trend, Caplan et al. (2011) measured individual-camera crime levels for both the "pre" and "post" installation periods via a location quotient (LQ). An LQ change towards the negative from the "pre" to "post" period suggested a crime reduction. Of the 73 camera viewsheds included in the analysis, 58 experienced reduced levels of shootings, with auto theft and theft from auto reducing in 34 and 41 viewsheds, respectively. Caplan et al. (2011) hypothesized that this variance in CCTV effect was due to the heterogeneity of certain factors across the viewsheds. 


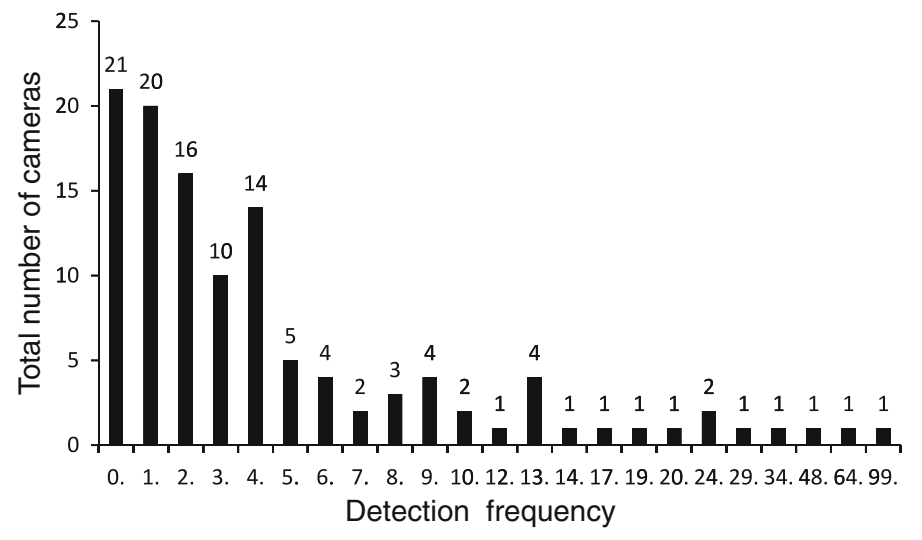

Fig. 2 Camera detection frequency

However, identifying and contextualizing the influence of such factors was beyond the scope of their study. The current study seeks to contribute to the literature by taking the next step towards contextualizing the influence of micro-level factors on CCTV camera effect.

\section{Methodology}

Units of Analysis

Units of analysis for the current study build upon the newly-developed viewshed methodology. We approached viewshed creation in a hands-on manner, similar to Ratcliffe et al. (2009). Researchers viewed the live feeds of the panning-mode ${ }^{2}$ of all CCTV cameras in Newark over the course of 5 months (April-September 2011) and digitized the viewshed of each site. A detailed GIS base map (with layers displaying streets, land parcels, building footprints and aerial imagery) was incorporated to ensure that the digitized viewsheds accurately reflected the physical landscape. For example, if the viewable area to the southeast of a camera was obstructed by a building, researchers "snapped" the viewshed boundaries to that building in order to accurately reflect the extent of the camera's view. We also took precautions to not overlook the insight of Newark's CCTV operators. Ratcliffe et al. (2009) similarly consulted with Philadelphia police officers to determine viewshed boundaries. In order to gain such perspective, at the conclusion of each visit to the control room, researchers met with the commander of the Video Surveillance Unit, who was asked to ascertain whether the viewsheds created during that visit accurately reflected

\footnotetext{
$\overline{2}$ When manually controlled by a user, each camera has the ability to see further than what is visible in panning mode. However, the panning mode was digitized as the viewshed for two reasons. One, given the large camera to operator ratio all of the cameras are in "panning mode" more often than they are actively controlled by an operator. Secondly, constructing the viewshed based on a camera's possible view would lead to areas significant distances away from the camera being designated as part of the viewshed. For example, Newark officials demonstrated to us that a camera on top of an office building was able to view airline logos on airplanes parked at Newark Liberty International Airport over a mile away. Creating viewsheds based on this capacity would lead to an over-estimation of CCTV coverage, similar to the problem encountered when aggregate geographies serve as units of analysis.
} 


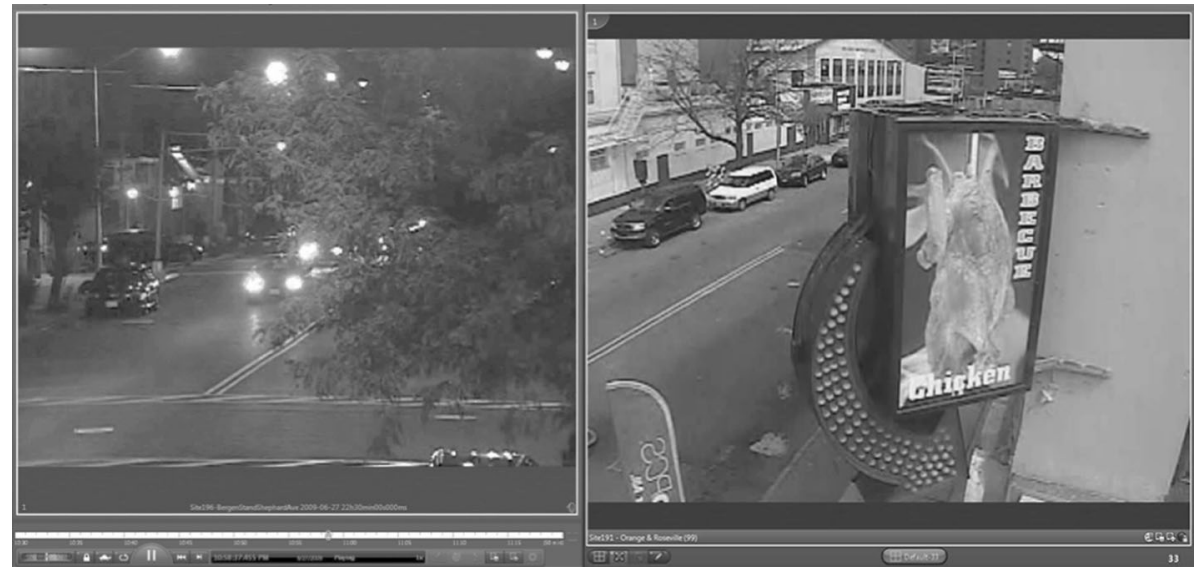

Fig. 3 Line-of-sight obstructions

the areas covered by the cameras' line-of-sight. There was a high level of agreement between the commander and the research staff. ${ }^{3}$

This study's methodology further builds upon previous research by denoting areas within viewshed boundaries obstructed from view. While previous studies digitize overall camera coverage, such procedures do not allow for the identification of ground level objects that commonly impede a camera's visibility (see Fig. 3). Viewsheds created for this study accounted for two particular obstructions: (1) immovable objects (e.g. traffic signs and telephone poles), and (2) foliage (e.g. leaves from trees and bushes) (see Fig. 4). ${ }^{4}$

An accompanying catchment zone was created for each viewshed to allow for a test of displacement and diffusion of benefits (Clarke and Weisburd 1994). Following the approach of Ratcliffe et al. (2009), catchment zones began as 291 foot buffers around each viewshed, to reflect the median block size in Newark. The buffers were adjusted to take into account local geography and road patterns surrounding each viewshed. While this approach creates zones of slightly varying sizes, it reflects the variability of street networks around cameras. As explained by Ratcliffe et al. (2009), “... the use of actual camera viewsheds can mean that a ... buffer stretches to just short of a neighboring intersection. In

\footnotetext{
3 A small level of disagreement occurred regarding the visible extent of a handful of rooftop cameras. In these instances, the commander believed the viewsheds extended over too large an area, leading the researchers to redraw the viewsheds to a more concise area. However, all of the rooftop viewsheds were part of a group of cameras that were excluded from the analysis (which will be discussed later on), rendering this small disagreement between the researchers and commander moot.

${ }^{4}$ We originally considered excluding these areas from the final viewsheds. However, we decided against this approach in recognition of the imprecise nature of crime location data. For example, at one camera site the northwest corner of an intersection was obstructed from view by a building awning. A manual review of the crime reports for 10 incidents occurring at this intersection found that officers did not denote the precise corner where the offense took place in a single instance. This prevented us from identifying whether the incidents occurred on the obstructed corner, or one that was visible to CCTV. Since police officers commonly record incident locations as intersections rather than specific addresses (Braga et al. 2011: 15) we decided against excluding the obstructed areas from the viewsheds.
} 


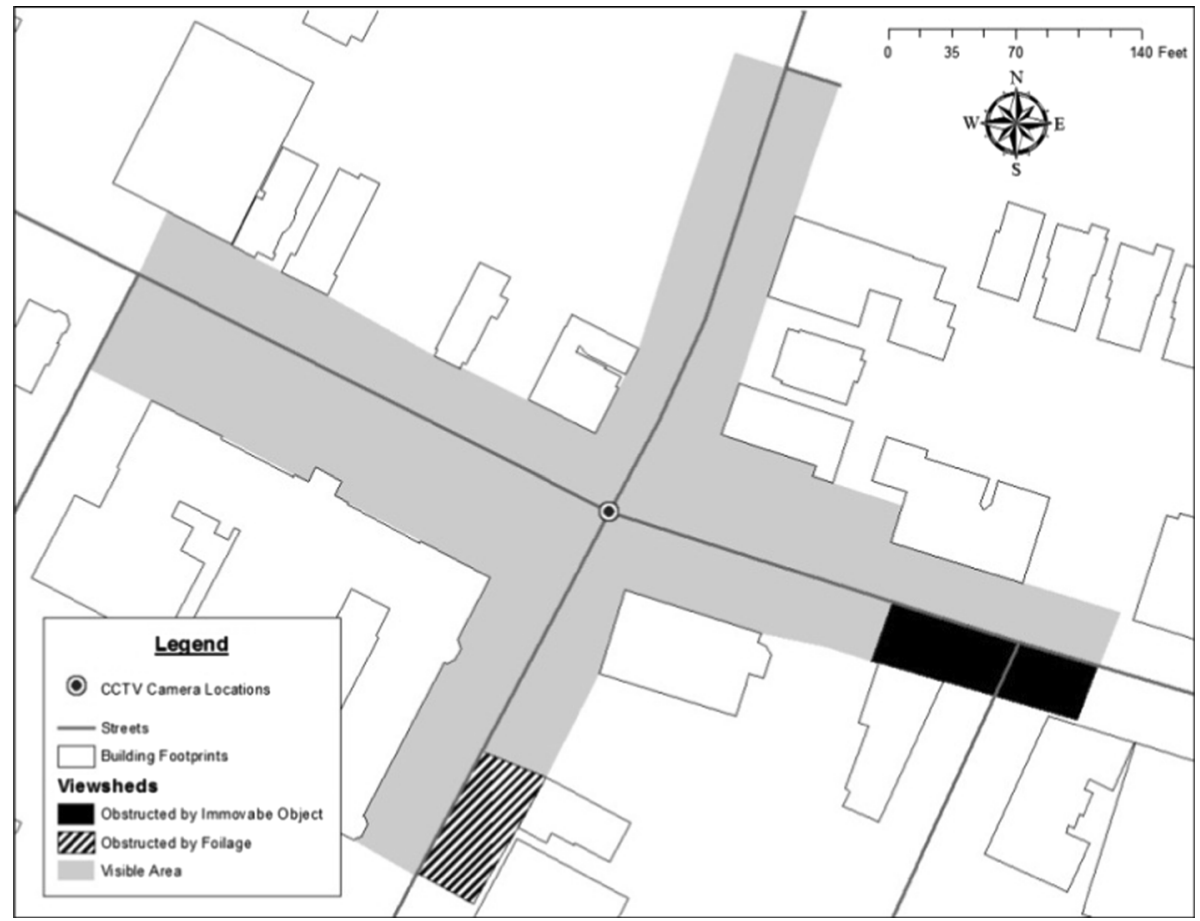

Fig. 4 Example viewshed with denoted areas of obstruction

circumstances like this, the addition of an extra $20 \mathrm{ft}$. is sufficient to include the street intersection ... and create a buffer that is a more realistic approximation of the likely displacement area" (752). With this in mind, when a buffer was half a block or less from the nearest intersection, the catchment zone was extended to the intersection. Otherwise, the catchment zone was constricted to the buffer (see Fig. 5).

This process resulted in the creation of viewsheds and catchment zones for 141 of the system's 146 cameras. Five cameras were out of service for about a year and were thus unable to be viewed. Thirteen viewsheds were excluded due to the police department having imprecise information regarding their installation dates. ${ }^{5}$ Overlapping viewsheds were considered as single sites to protect against the multiple counting of individual crime incidents falling within more than one viewshed (Ratcliffe et al. 2009); 18 viewsheds overlapping with at least one other viewshed were combined into seven cases. After these adjustments, the analysis included 117 viewsheds installed over four dates: 3/15/08 (44), 7/31/08 (50), 12/10/09 (13), and 4/23/10 (10).

\footnotetext{
5 The Newark Police Department recorded the installation date of 11 cameras as 6/8/2007, coinciding with the official formation of the Video Surveillance unit. However, according to those directly involved with the camera deployment, installation of these cameras occurred during a "test phase" spanning several months in 2006 with intermittent monitoring of the cameras beginning as early as February 2007. Two additional cameras were unable to transmit footage to the control room for over a year after their installation, likewise leading to their exclusion.
} 


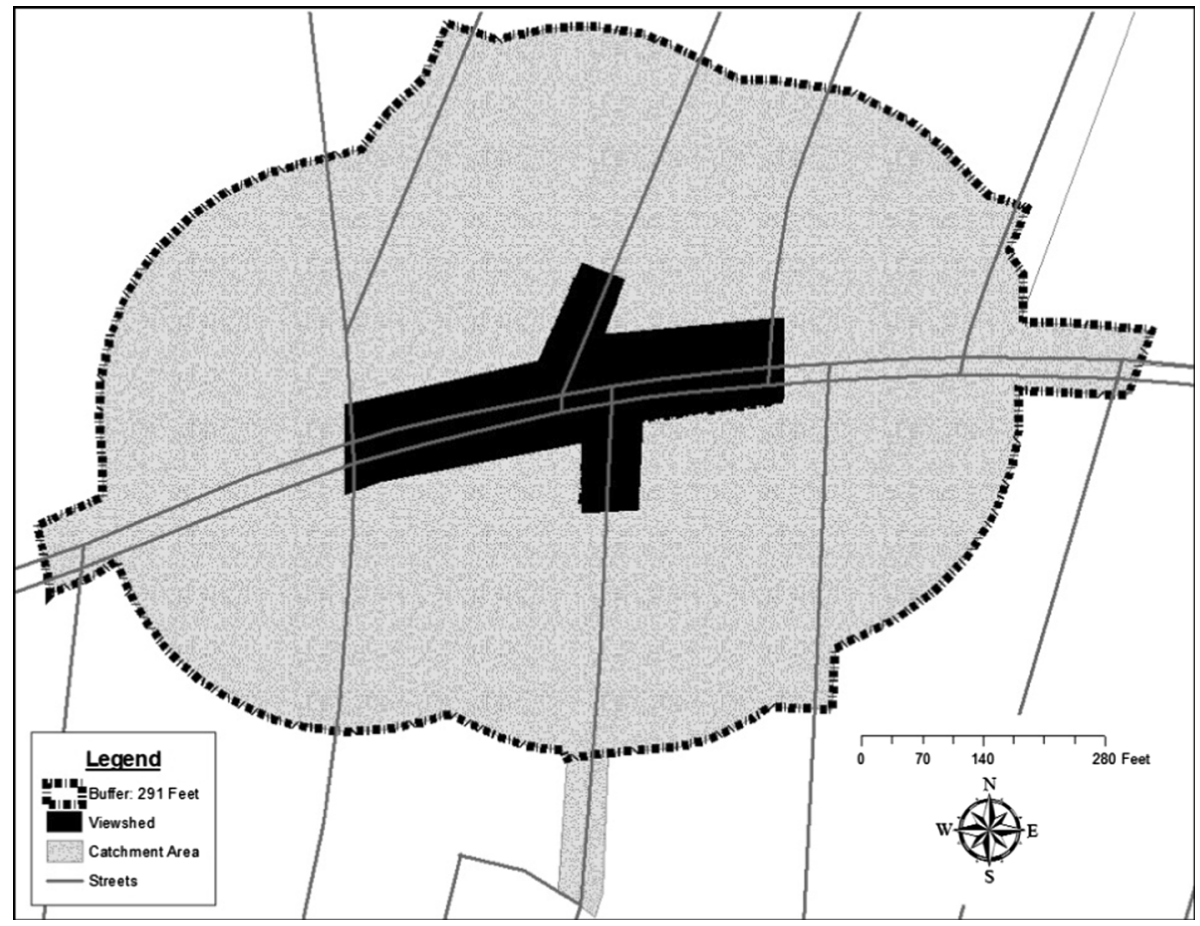

Fig. 5 Example catchment zone with respective viewshed and 291 foot buffer

\section{Dependent Variable: Camera Effect on Crime}

Camera effect was determined by measuring crime level changes within each viewshed, from the 1-year pre-installation period to the 1-year post-installation period. ${ }^{6}$ While previous studies have given little consideration to the locations where crimes occur, CCTV's deterrent effects are likely limited to public areas that can potentially be viewed on camera. Since the increased "risk" suggested by camera presence is lost on potential offenders indoors (who cannot see public cameras), crime occurring out of public view (e.g. a domestic assault in a residence) should not be included in an evaluation of CCTV in order to preserve construct validity (Cameron et al. 2008; Caplan et al. 2011).

The analysis was initially designed to only include crimes occurring outdoors. The Newark Police Department's GIS files for the years 2008-2010 include a variable denoting whether the crime occurred indoors or outdoors, facilitating the identification of such incidents. However, the analysis necessitated the use of crime incidents from as far back as 2007 in order to account for the pre-installation period of cameras installed in 2008. Unfortunately, the Newark Police Department's pre-2008 GIS files do not include the "indoor/outdoor" variable. Therefore, we incorporated crime types that predominantly

\footnotetext{
${ }^{6}$ While some cameras were in place for longer than 1 year, having uniform pre/post periods allows for a more accurate comparison of sites. Previous research has found that place-based police interventions sometimes exhibit "deterrence decay" after their initial deployment (Sherman 1990), including CCTV (Mazerolle et al. 2002). Restricting the study period to 1-year ensures that camera effectiveness is measured in a uniform way, by testing the initial impact of each camera while excluding any existing deterrence decay effects.
} 
Table 1 Crime incidents occurring indoors/outdoors in Newark, 2008-2010

\begin{tabular}{lrrrrr}
\hline Crime & \multicolumn{1}{c}{ Total } & Outdoor & \% outdoor & Indoor & \% indoor \\
\hline Aggravated assault & 3,250 & 2,076 & 63.88 & 1,174 & 36.12 \\
Auto theft & 10,958 & 10,886 & 99.34 & 72 & 0.66 \\
Burglary & 5,966 & 397 & 6.65 & 5,569 & 93.35 \\
Murder & 219 & 177 & 80.82 & 42 & 19.18 \\
Robbery & 4,566 & 3,732 & 81.73 & 834 & 18.27 \\
Shootings & 864 & 767 & 88.77 & 97 & 11.23 \\
Theft & 4,555 & 1,573 & 34.53 & 2,982 & 65.47 \\
Theft from auto & 6,817 & 6,737 & 98.83 & 80 & 1.17 \\
\hline
\end{tabular}

occur outdoors instead of crime incidents that did occur outdoors. From 2008 through 2010, murder, robbery, non-fatal shootings, auto theft, and theft from auto occurred outdoors over $80 \%$ of the time-with no other crimes occurring outdoors in more than $63.88 \%$ of cases-and were thus included in the analysis (see Table 1). ${ }^{7}$

Crime data were classified into six different categories. All of the crime types (robbery, murder, shootings, auto theft, and theft from auto) were combined to create an "overall crime" category. Robbery, murder, and shootings were combined to create a "violent crime" category. Auto theft and theft from auto were combined to create a "property crime" category. Robbery, auto theft, and theft from auto were each included on their own as disaggregate categories. Murder and shootings were not included as disaggregated categories due to their sparse occurrence, compared to the other crime categories (see Table 1).

Following the approach of Caplan et al. (2011), crime levels were measured via Location Quotients (LQ), which measure the occurrence of crime in a target area compared to its occurrence over a larger control area. LQs allow for the easy identification of areas with crime levels "at the expected region-wide rate, areas that have lower levels of crime, and areas that are 'hotter' than expected" (Ratcliffe 2010: 18). LQs add perspective to crime totals by controlling for two important factors: (1) the size of the target area and (2) crime incidence within a control area. The first factor is important in the current study due to the varying sizes of the viewsheds. The second factor is important since the comparison of a target area with a control area is considered the minimal interpretable research design (Cook and Campbell 1979).

LQs were calculated for each viewshed via the following equation:

$$
\mathrm{LQ}=\left(x_{i} / t_{i}\right) /(X / T),
$$

where $x_{i}$ represents the number of crimes in viewshed $i ; t_{i}$ represents the total area of viewshed $i$; and $\mathrm{X}$ and $\mathrm{T}$ represent the numbers of crimes of type $\mathrm{x}$ within the surrounding

\footnotetext{
$\overline{7}$ While being captured in police reports as an indoor crime, burglary certainly is significantly related to outdoor activities of offenders, who must first breach the outer structure of a property in order to get indoors. However, we decided against including burglary in the analysis due to potential inaccuracies in Newark's 2007 Burglary GIS files. In 2008, Newark Police officials conducted an audit of all burglary and indoor theft incidents occurring in 2006 and 2007 to ensure the proper classification of each incident. With the introduction of an electronic Records Management system, it was discovered that the "upgrading" or "downgrading" following the initial investigation of property crime oftentimes was not reflected in the crime statistics. While the crime reports and UCR statistics were corrected to reflect the results of the audit, Newark officials were unclear whether the 2007 GIS files were updated.
} 
police precinct and the area of the surrounding police precinct, respectively. ${ }^{8}$ LQ values below one suggest the area to have less crime than is more generally found across the aggregate geography; LQ values greater than one suggest a crime concentration. As explained by Brantingham and Brantingham (1998: 271), an LQ of 1.4 shows that crime is $40 \%$ higher than the aggregate trend while a value of 0.7 suggests the area to be $30 \%$ below the aggregate trend.

Two separate LQs were calculated for each viewshed, for the 1-year "pre" and for the 1-year "post" periods. Each viewshed's "pre" LQ was subtracted from the "post" LQ, creating a "Change in Location Quotient" ( $\Delta \mathrm{LQ}$ ) variable. Negative $\Delta \mathrm{LQ}$ values were considered as evidence of crime reductions while positive $\Delta$ LQ values suggest increasing crime levels (Caplan et al. 2011). $\Delta$ LQ values were calculated for all six crime categories.

In order to maintain the internal validity of the dependent variable, we excluded incidents falling within viewshed catchment zones when calculating the LQs. This was done to ensure that geographic displacement was not confused with a deterrence effect. For example, if crime incidents are displaced from a camera's viewshed to its catchment zone post-installation, the $\Delta \mathrm{LQ}$ variable would identify this as evidence of a crime reduction (e.g. the crime incidents within the viewshed decreased while incidents within the precinct increased). By excluding incidents that occurred within the catchment zone we ensure that crime levels in the surrounding precinct are completely unrelated to CCTV, maintaining the validity of the $\Delta \mathrm{LQ}$ variables. ${ }^{9}$

Catchment zones for all viewsheds with negative $\Delta \mathrm{LQ}$ values were included in a subsequent analysis of displacement. Similar to the main analysis, "pre" and "post" LQs were calculated for the catchment zones with negative $\Delta \mathrm{LQ}$ values suggesting a crime reduction and positive values suggesting an increase. As previously discussed, the numerator of the LQ formula divides the number of crime incidents within the target area by the overall square footage of the target area. Therefore, it should be mentioned that the square footage of the catchment zones were calculated in a slightly different manner than the viewsheds. To review, viewshed boundaries were constricted by surrounding buildings, a function of researchers digitizing viewsheds by viewing actual camera feeds. Since catchment zones were constructed via geoprocessing functions in ArcGIS they extended over space occupied by buildings in the real world. To remove the influence of these indoor areas on the LQ formula, we subtracted the square footage of the building footprints falling within each catchment area from the overall square footage of the catchment zone to derive $t_{i}$ in the LQ formula. ${ }^{10}$ This ensured that the catchment zones represented publically

\footnotetext{
${ }^{8}$ While Caplan et al. (2011) calculated LQs based on city-wide crime and geography figures, we chose to utilize each viewshed's surrounding precinct as its control area. This is in recognition of the fact that local crime levels are highly contingent upon localized factors, including the influence of localized police practices, which may vary across precincts. By comparing viewsheds with encompassing precincts, we ensure that the control areas were susceptible to the same organizational forces that affected the viewsheds (Ratcliffe et al. 2009: 752-753).

${ }^{9}$ Hypothetically, CCTV cameras may displace crime by a distance greater than the reach of the catchment zone. In such cases, the "displaced" crime incidents would get calculated in the LQ statistics. However, empirical research has demonstrated that the likelihood of spatial displacement decreases as the distance from the target area increases (Bowers and Johnson 2003; Eck 1993). Therefore, a distance of only a block or two is generally accepted as an appropriate boundary for a test of displacement (Weisburd and Green 1995). Our catchment zones adhere to this principle while also following the approach of previous CCTV studies (Caplan et al. 2011; Ratcliffe et al. 2009). Therefore, we consider the risk of displaced crimes occurring outside of the catchment zone to be commensurate with that of previous crime-and-place studies.

${ }^{10}$ Researchers measured the area of building footprints falling within each catchment zone by utilizing the "clip" function of ArcToolbox and then calculating the total square footage of the resulting shapefile.
} 
accessible areas, similar in scope to the geography denoted by viewsheds, and prevented $\Delta \mathrm{LQ}$ values in catchment zones from being substantially lower than their viewshed counterparts (due to an inflated "area" caused by inclusion of the indoor spaces). This process was utilized in both the LQ formulas for crime incidents as well as the LQ formulas for the environmental features discussed in the following section.

\section{Independent Variables}

Sixteen covariates were included in the statistical models. Variables were grouped into four categories: environmental features (nine), line-of-sight (three), enforcement activity (three), and camera design (one). The operationalization of each independent variable is discussed below.

\section{Environmental Features}

Nine independent variables capture the environmental context of each camera site. Eight were included in the analysis due to their status as crime generators or crime attractors (Brantingham and Brantingham 1995) as per previous empirical research: bars (Ratcliffe 2012; Scott and Dedel 2006); liquor stores (Bernasco and Block 2011); schools (Roncek 2000); general retail shops (Bernasco and Block 2011; Felson 2002); corner grocery stores (Bernasco and Block 2011; Myers 2002); take out eateries and fast food restaurants (Bernasco and Block 2011; Kennedy et al. 2011); public transit stops (Block and Block 1999; Smith and Clarke 2000); and public housing and privately owned "at-risk" housing complexes (Eck 1994; Zanin et al. 2004). ${ }^{11}$ Parking lots were included in recognition of previous research showing them to be areas conducive to the effect of CCTV (Gill and Spriggs 2005; Farrington et al. 2007; Welsh and Farrington 2009).

A number of the environmental features were collected from Newark Police Department databases, ${ }^{12}$ with the remainder obtained from InfoGroup (www.infogroup.com), a leading provider of residential and commercial information for reference, research, and marketing purposes. ${ }^{13}$ Most datasets were point GIS layers, geocoded to street centerlines according to their address. ${ }^{14}$ The parking lots file was a GIS polygon layer containing all land parcels zoned as "parking lots" by the City of Newark. The "at-risk" housing file, created and maintained by the Newark Police Department's CompStat unit through a partnership with the Newark Housing Authority and various City of Newark departments, is a GIS polygon layer containing land parcels with particular types of housing complexes. In addition to public housing units, the at-risk housing file includes privately-owned complexes similar in scope to public housing complexes, in recognition of previous analyses finding that such complexes contribute to crime in a similar manner as public housing in Newark (Kennedy

\footnotetext{
11 While some of the above features can be categorized together based on certain similarities, disaggregating these micro-features minimizes potential threats to content validity that can surface through considering different areas as if they were the same (Stucky and Ottensmann 2009). For example, since bars and liquor stores have different hours of operation in Newark (liquor stores close at 10:00 p.m. while bars may remain open well after 2:00 am) they likely have differing influence on crime occurrence despite both being classified as "liquor establishments."

12 Bars, liquor stores, schools, transit stops, "at-risk" housing, and parking lots.

13 Take-out eateries, corner stores, and general retail shops. Since the Newark Police Department was not in possession of this data, we were unable to cross validate the data to test their validity.

14 Bars, liquor stores, schools, general retail shops, corner stores, take out eateries and fast food restaurants, and public transit stops.
} 
et al. 2011; Piza and O'Hara 2012; Zanin et al. 2004). City of Newark personnel identified all residential buildings in the city with 10 or more units with similar structural attributes as public housing (e.g. single entrances, limited automobile accessibility to the courtyard, etc.) that received government subsidies for renting to low-income tenants. ${ }^{15}$ Privately owned complexes fitting these criteria were merged with public housing to create the "atrisk" housing layer.

An important consideration is the proximity at which the spatial influence of these features (Caplan 2011) may affect activity within viewsheds. As previously discussed, viewsheds accurately denote areas monitored by CCTV; the measurement of crime levels within these boundaries is a valid metric of CCTV effect (Caplan et al. 2011; Ratcliffe et al. 2009). However, it is impractical to consider features falling in the surrounding area of a camera but outside of a viewshed (e.g. a bar across the street or immediately around the corner) to be unrelated to within-viewshed activity. We thus measured the prevalence of the environmental features within the "environmental backcloth" (Brantingham and Brantingham 1981) of camera sites. This method effectively captures the person-space interaction reported by environmental criminologists (Brantingham and Brantingham 1993; Felson 2002; Taylor and Harrell 1996) as well as scholars in the field of geography (Freundschuh and Egenhofer 1997; Ittelson 1973).

Operationalizing the environmental backcloth of each camera site was a two-step process. First, the camera's maximum visibility (the number of feet from the camera to the furthest extent of its viewshed) was measured via the "measurement tool" in ArcGIS. A buffer of this distance was then generated around the camera. ArcGIS's "clip" function was utilized to truncate the features of the underlying data layers based upon the outline of the buffer. This process was repeated for each viewshed included in the analysis. The prevalence of each feature was measured through a Location Quotient (LQ) controlling for the area of the environmental backcloth as well as the distribution of the feature across the entirety of the study area. ${ }^{16}$ The process differed slightly by the data type. LQs for the point features controlled for the overall length of street segments, to reflect the geocoding method employed with this data (to street centerlines) (see Fig. 6). LQs for the polygonal features controlled for the square footage of the polygons, buffer, and overall study area (see Fig. 7). ${ }^{17}$

\section{Line-of-Sight}

Previous research suggests CCTV coverage and dosage to be related to camera effectiveness (Farrington et al. 2007; Gill and Spriggs 2005). In this sense, three variables related to camera coverage are included. The first, named "overlap," identifies the number of individual cameras comprising the viewshed. To review, several overlapping viewsheds were merged into singular viewsheds in order to prevent single incidents from being counted multiple times; the overlap variable identifies whether the viewshed depicts the

\footnotetext{
15 The CompStat unit informed us that they received this information from the City of Newark's Office of Housing Assistance.

${ }^{16}$ The final study area excluded the portion of Newark comprised of Newark Liberty Airport and the (shipping) Port of Newark, which are outside of the Newark Police Department's jurisdiction. Outside of the airport and port, the area is almost entirely comprised of highways and vacant land, with activity primarily taking the form of long-distance motor vehicle traffic with little-to-no pedestrian activity. Due to these reasons, coupled with the fact that no CCTV cameras were installed in this area, this area was excluded from the final study area.

${ }^{17}$ See Piza (2012: 80-85) for a more in-depth demonstration of the LQ calculation for the environmental features.
} 


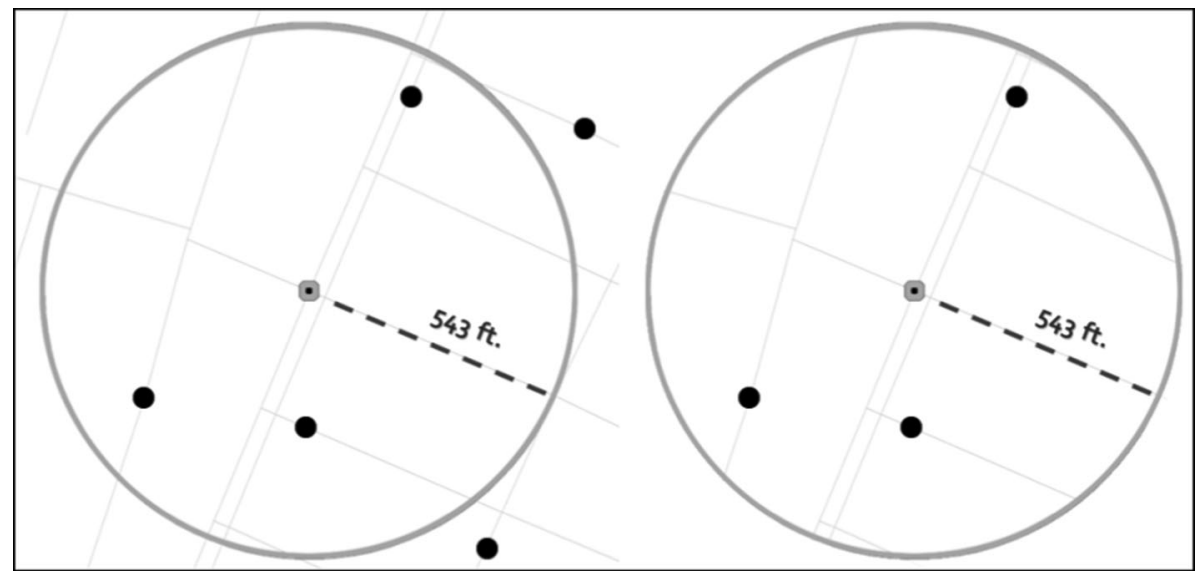

Fig. 6 Clip process for point environmental features

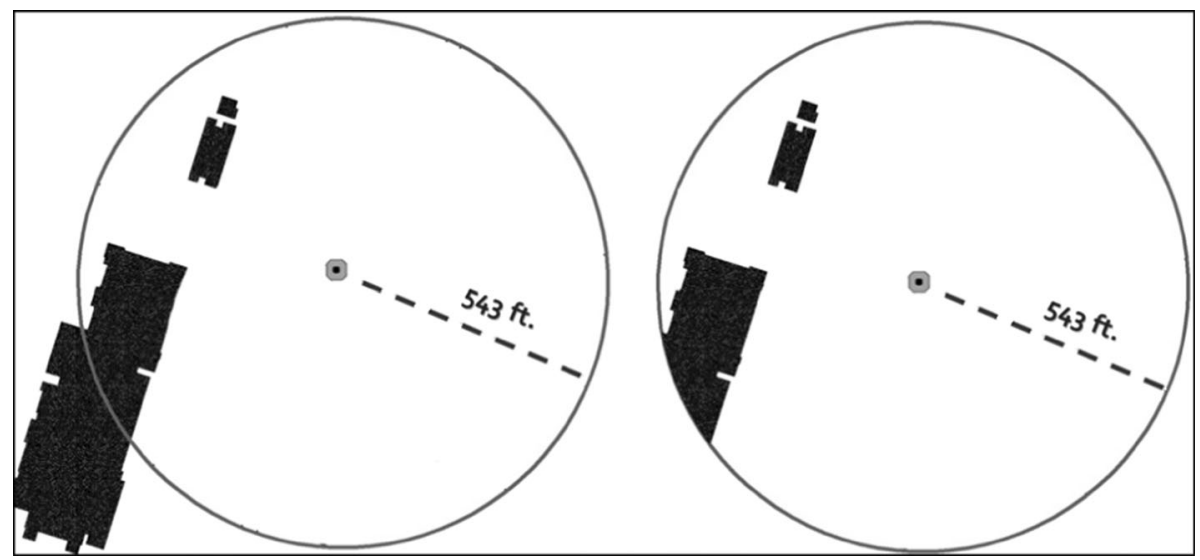

Fig. 7 Clip process for polygon environmental features

line-of-sight of a single camera or multiple cameras. Two variables measure visible obstructions within viewsheds. These variables are the percentage of the overall viewshed that is blocked by foliage and the percentage of the viewshed that is obstructed by immovable objects. While the influence of visible obstructions has yet to be empirically tested, anecdotal evidence suggests it can impede upon the live monitoring of cameras (Gill et al. 2005, 2006; Keval and Sasse 2010; Smith 2004).

\section{Enforcement Actions}

Three variables measure the enforcement actions conducted in viewsheds. The first two variables measure the proactive use of CCTV: (1) the number of criminal incidents detected by each camera, and (2) enforcement activity (e.g. arrest, summons, or field interrogation) in response to said detections. These data were considered measures of the proactive use of CCTV, in recognition of previous research finding proactive surveillance 
activity to be related to crime reduction (La Vigne et al. 2011). Statistically significant negative regression coefficients would suggest that cameras sites experiencing high levels of proactive CCTV activity experienced more pronounced reductions of crime levels than camera sites with lower amounts of CCTV activity. The data were collected from weekly Video Surveillance Unit (VSU) activity reports, which capture the nature, address, outcome, and camera site of each CCTV detection. Data from the VSU reports were entered into a separate database in order to calculate the number of detections and enforcement actions occurring within each viewshed during their respective 1-year post-installation periods. The third enforcement variable controls for the potential effect of arrests unrelated to the surveillance system. ${ }^{18}$ GIS arrest files, which contain all arrests enacted by the Newark Police Department, were cross-referenced with VSU reports to identify those generated by the CCTV unit. The CCTV-generated arrests were removed from the arrest file, leaving only those arrests unrelated to the surveillance operation. We then conducted a "spatial join" within ArcGIS to identify the number of unrelated arrests that took place within each viewshed over their respective 1-year post-installation periods.

\section{Camera Design}

The camera design variable is a dummy variable identifying each camera as a "dome" camera (1) or not (0) in recognition of previous research that suggests traditionally designed overt cameras may have decreased deterrent effects compared to semi-covert "dome" cameras (Waples and Gill 2006). For the seven viewsheds that were comprised of multiple cameras, the average of the dichotomous values was calculated. For example, if a viewshed is comprised of three dome cameras, the resulting "dome" variable is 1 $([1+1+1] / 3=1)$. However, if the viewshed is comprised of two dome cameras and one bullet resistant camera the camera design value would be $0.66([1+1+0] / 3=0.66)$. Statistically significant regression coefficients (in either direction) would suggest that one camera design style produces more of a deterrent effect than the other.

\section{Summary of Variable Distribution}

Table 2 provides a summary of the variables. As suggested by the means and standard deviations, a fair amount of variance exists within each variable. In respect to the dependent variables, Newark's CCTV system is comprised of both effective and ineffective camera sites. For each crime category the number of viewsheds with negative $\Delta \mathrm{LQ}$ values, suggestive of crime decreases, and positive $\triangle \mathrm{LQ}$ values, suggestive of crime increases, is nearly even, which parallels the findings of Ratcliffe et al. (2009) in Philadelphia, as well as the findings of Caplan et al. (2011) in Newark. ${ }^{19}$

\section{Statistical Approach}

For the analysis, $\Delta \mathrm{LQ}$ values were utilized as dependent variables in ordinary least squares (OLS) regression models. OLS rests on particular assumptions that many times are not met

\footnotetext{
18 While total "enforcement actions" are measured in respect to the CCTV operation, observations of unrelated police activity are restricted to arrests. This is due to city-wide enforcement data being unavailable for all other enforcement actions (e.g. "summonses") prior to 2009.

${ }^{19}$ Given the similarities between Caplan et al. (2011) and the current study, a comparison of their respective $\Delta \mathrm{LQ}$ distributions appears in the "Appendix" section.
} 
Table 2 Statistical summary of dependent and independent variables

\begin{tabular}{|c|c|c|c|c|c|c|}
\hline & Mean & SD & Min & Max & \# negative $(\%)$ & \# positive $(\%)$ \\
\hline \multicolumn{7}{|l|}{ Dependent variables } \\
\hline$\Delta \mathrm{LQ}$ overall crime & 0.005 & 0.563 & -1.840 & 1.643 & $55(47.01)$ & $62(52.99)$ \\
\hline$\Delta \mathrm{LQ}$ violent crime & -0.072 & 1.570 & -6.310 & 2.739 & $50(42.74)$ & $62(52.99)$ \\
\hline$\Delta \mathrm{LQ}$ property crime & -0.043 & 0.553 & -1.739 & 1.133 & $58(49.57)$ & $57(48.72)$ \\
\hline$\Delta \mathrm{LQ}$ robbery & -0.079 & 1.719 & -6.037 & 3.548 & $54(46.15)$ & $57(48.72)$ \\
\hline$\Delta \mathrm{LQ}$ auto theft & -0.033 & 0.607 & -2.295 & 1.570 & $54(46.15)$ & $60(51.28)$ \\
\hline$\Delta \mathrm{LQ}$ theft from auto & -0.067 & 1.095 & -3.676 & 3.782 & $61(52.14)$ & $48(41.03)$ \\
\hline \multicolumn{7}{|l|}{ Independent variables } \\
\hline \multicolumn{7}{|l|}{ Environmental features } \\
\hline Bars LQ & 1.417 & 2.275 & 0.000 & 10.179 & - & - \\
\hline Liquor stores LQ & 2.863 & 5.408 & 0.000 & 25.724 & - & - \\
\hline Corner stores LQ & 2.415 & 3.399 & 0.000 & 14.600 & - & - \\
\hline General retail shops LQ & 4.266 & 11.604 & 0.000 & 73.209 & - & - \\
\hline Schools LQ & 1.684 & 3.335 & 0.000 & 16.810 & - & - \\
\hline Take out LQ & 2.459 & 3.536 & 0.000 & 22.582 & - & - \\
\hline Transit stops LQ & 2.220 & 1.666 & 0.000 & 7.077 & - & - \\
\hline Housing LQ & 5.253 & 10.982 & 0.000 & 60.806 & - & - \\
\hline Parking lots LQ & 7.000 & 11.901 & 0.000 & 63.360 & - & - \\
\hline \multicolumn{7}{|l|}{ Line of sight } \\
\hline Overlap & 1.085 & 0.406 & 1.000 & 4.000 & - & - \\
\hline Overall $\%$ obstructed & 17.912 & 11.501 & 0.000 & 55.633 & - & - \\
\hline$\%$ immovable obstruct & 6.452 & 7.156 & 0.000 & 28.447 & - & - \\
\hline$\%$ foliage obstruct & 11.460 & 10.564 & 0.000 & 53.154 & - & - \\
\hline \multicolumn{7}{|l|}{ Enforcement actions } \\
\hline Detections & 6.299 & 12.545 & 0.000 & 99.000 & - & - \\
\hline Camera enforcement & 1.906 & 5.674 & 0.000 & 55.000 & - & - \\
\hline Unrelated arrests & 50.453 & 88.284 & 0.000 & 865.000 & - & - \\
\hline \multicolumn{7}{|l|}{ Camera design } \\
\hline Dome & 0.838 & 0.370 & 0.000 & 1.000 & - & - \\
\hline
\end{tabular}

with criminology data (Maxfield and Babbie 2001: 404). Therefore, the analysis began with a test of key assumptions of OLS, all of which were conducted in Stata 12: normality, homoscedasticity, proper model specification, and an absence of multicollinearity (McClendon 1994).

To test normality, a Kolmogorov-Smirnov $(\mathrm{K}-\mathrm{S})$ test was conducted on each of the six dependent variables to identify whether the distribution significantly differed from a standard normal distribution (Chakravart et al. 1967: 392-394). Five exhibited statistically insignificant $p$ values, indicative of a normal distribution. The lone exception was robbery $(p=0.038)$. Thus, the robbery $\Delta \mathrm{LQ}$ variable was squared in order to approximate a normal distribution. Following the transformation, the $p$ value was insignificant $(p=0.392) .^{20}$

${ }^{20}$ A "ladder of powers" (Tukey 1977) function performed in STATA 12.0 identified the square transformation as the only procedure to approximate a normal distribution. 
A Cook-Weisberg test of homoscedasticity was conducted through the "hettest" command, with $p<0.05$ rejecting the null hypothesis that variance is homogenous (Hamilton 2013: 165). The "linktest" command was run to measure the potential presence of model specification errors. Linktest creates two new variables: “_hat," the variable of prediction, and "_hatsq," the variable of squared prediction. The model is then refit using these two variables as predictors, with "_hat" expected to be significant since it's the predictor variable and "_hatsq" expected to be insignificant because squared predictors should have no explanatory power if the model is correctly specified (UCLA 2007). Lastly, we measured the presence of multicollinearity amongst the independent variables by performing a post hoc calculation of the variance inflation factor (VIF) for each of the model covariates. We specifically recorded the tolerance of each covariate (defined as $1 / \mathrm{VIF}$ ), which displays the proportion of the covariate's variance that is independent of the other variables (Hamilton 2013: 203). A tolerance value lower than 0.1 suggests that the covariate is significantly correlated with others in the model (UCLA 2007).

The results of the Kolmogorov-Smirnov normality tests, Cook-Weisberg heteroscadacity tests, and the model specification test show that all of the models adhere to the previously stated OLS assumptions. Furthermore, all tolerance values (1/VIF) are well above the 0.1 threshold, showing that the covariates do not suffer from multicollinearity. ${ }^{21}$

\section{Findings}

\section{Crime Level Changes in Viewsheds}

Tables 3 and 4 display the findings of the statistical analysis. Along with $\beta$ values, associated standard errors and statistical significance, the tables report the coefficient of determination and statistical power of each model. Since the number of observations $(\mathrm{N}=117)$ is somewhat low considering the number of covariates (16) we wanted to ensure that the models were sufficiently powered to detect statistical significance. Five of the six models exhibited statistical power greater than 0.80 , as measured with $G^{*}$ Power software (Faul et al. 2009), meeting the minimum threshold for statistical power (Britt and Weisburd 2010). The lone exception was the "overall crime" model, with a power of 0.638. The underpowered nature of this model makes it vulnerable to falsely failing to reject the null hypothesis (Type II error).

Table 3 displays the findings for the aggregate crime categories: overall crime, violent crime, and property crime. Environmental features were statistically significant in the violent crime and property crime models. Bars were statistically significant in the violent crime model, associated with reduced crime levels. For property crime, retail stores were significantly associated with crime level increases. Line-of-sight variables were statically significant in the violent crime model, but not in the expected direction, with immovable obstructions being associated with a crime decrease. The camera enforcement variable was statistically significant and associated with reduced crime levels for overall crime and violent crime.

Table 4 displays the findings for the disaggregate categories: robbery, auto theft, and theft from auto. Similar to the aggregate categories, each of the disaggregate crimes was

${ }^{21}$ Due to space constraints, results of the OLS diagnostic tests are not presented in text, but are available from the lead author upon request. 
Table 3 OLS results for aggregate crime categories (viewsheds)

\begin{tabular}{|c|c|c|c|c|c|c|c|c|c|}
\hline \multirow[t]{2}{*}{ Variables } & \multicolumn{3}{|c|}{ Overall crime } & \multicolumn{3}{|c|}{ Violent crime } & \multicolumn{3}{|c|}{ Property crime } \\
\hline & $\beta$ & SE & $\mathrm{t}$ & $\beta$ & SE & $\mathrm{t}$ & $\beta$ & SE & $\mathrm{t}$ \\
\hline \multicolumn{10}{|l|}{ Environmental features } \\
\hline Bars & -0.045 & 0.027 & -1.710 & $-0.195 * *$ & 0.066 & -2.950 & -0.026 & 0.025 & -1.010 \\
\hline Liquor stores & 0.013 & 0.011 & 1.190 & 0.027 & 0.027 & 1.020 & 0.007 & 0.010 & 0.660 \\
\hline Corner stores & 0.006 & 0.018 & 0.330 & 0.019 & 0.045 & 0.430 & 0.002 & 0.017 & 0.090 \\
\hline Retail stores & 0.011 & 0.007 & 1.660 & -0.013 & 0.017 & -0.780 & $0.019^{*}$ & 0.006 & 3.010 \\
\hline Schools & 0.023 & 0.017 & 1.330 & 0.001 & 0.044 & 0.020 & 0.025 & 0.017 & 1.470 \\
\hline Take outs & -0.005 & 0.019 & -0.280 & 0.016 & 0.046 & 0.350 & -0.016 & 0.018 & -0.890 \\
\hline Transit stops & 0.007 & 0.038 & 0.180 & -0.031 & 0.095 & -0.320 & 0.000 & 0.037 & 0.000 \\
\hline At-risk housing & -0.001 & 0.005 & -0.210 & 0.004 & 0.014 & 0.280 & -0.001 & 0.005 & -0.130 \\
\hline Parking lots & -0.001 & 0.005 & -0.240 & 0.012 & 0.012 & 0.960 & -0.003 & 0.005 & -0.550 \\
\hline \multicolumn{10}{|l|}{ Line of sight } \\
\hline $\begin{array}{l}\% \text { immovable } \\
\text { obstruct }\end{array}$ & -0.004 & 0.009 & -0.480 & $-0.047 *$ & 0.022 & -2.140 & 0.000 & 0.008 & 0.020 \\
\hline$\%$ foliage obstruct & -0.003 & 0.005 & -0.560 & -0.024 & 0.013 & -1.780 & -0.001 & 0.005 & -0.160 \\
\hline Overlap & 0.125 & 0.135 & 0.920 & 0.232 & 0.339 & 0.690 & 0.135 & 0.130 & 1.040 \\
\hline \multicolumn{10}{|l|}{ Enforcement activity } \\
\hline Detections & 0.013 & 0.008 & 1.530 & 0.015 & 0.021 & 0.750 & 0.011 & 0.008 & 1.420 \\
\hline Camera enforcement & $-0.045^{*}$ & 0.020 & -2.210 & $-0.121^{*}$ & 0.051 & -2.390 & -0.027 & 0.020 & -1.400 \\
\hline Unrelated arrests & 0.000 & 0.001 & -0.050 & 0.000 & 0.002 & 0.300 & 0.000 & 0.001 & -0.770 \\
\hline \multicolumn{10}{|l|}{ Camera style } \\
\hline Dome & 0.157 & 0.152 & 1.040 & 0.088 & 0.383 & 0.230 & 0.097 & 0.147 & 0.660 \\
\hline R-squared (adjusted) & \multicolumn{3}{|c|}{$0.122(-0.018)$} & \multicolumn{3}{|c|}{$0.296(0.183)$} & \multicolumn{3}{|c|}{$0.161(0.027)$} \\
\hline Power (1- $\beta$ err prob) & \multicolumn{3}{|l|}{0.638} & \multicolumn{3}{|l|}{0.997} & \multicolumn{3}{|l|}{0.814} \\
\hline
\end{tabular}

$* p<0.05 ; * * p<0.01$

differentially impacted by the environmental features. Bars were associated with reduced levels of robbery. Schools were associated with increased levels of auto theft. Both corner stores and retail stores were related to increased levels of theft from auto.

All of the disaggregate categories were influenced by line-of-sight variables. As observed in the violent crime model, immovable obstructions were associated with crime decreases in both the robbery and theft from auto models, while immovable obstructions were associated with increased levels of auto theft. Theft from auto was the only disaggregate crime category influenced by enforcement activity; the camera enforcement variable was significantly associated with decreased crime levels.

\section{Displacement and Diffusion of Benefits}

The current section explores any potential displacement or diffusion of benefits effects relative to the CCTV cameras. This analysis includes the catchment zones of all viewsheds with negative $\triangle \mathrm{LQ}$ values, suggestive of a crime reduction. Following the approach utilized in the viewshed creation, overlapping catchment areas were considered as single sites to prevent single incidents from being counted multiple times. This resulted in a total number of catchment zones smaller than the total viewsheds exhibiting negative $\Delta \mathrm{LQ}$ 
Table 4 OLS results for individual crime categories (Viewsheds)

\begin{tabular}{|c|c|c|c|c|c|c|c|c|c|}
\hline \multirow[t]{2}{*}{ Variables } & \multicolumn{3}{|c|}{ Robbery (squared) } & \multicolumn{3}{|c|}{ Auto theft } & \multicolumn{3}{|c|}{ Theft from auto } \\
\hline & $\beta$ & SE & $\mathrm{t}$ & $\beta$ & SE & $\mathrm{t}$ & $\beta$ & SE & $\mathrm{t}$ \\
\hline \multicolumn{10}{|l|}{ Environmental features } \\
\hline Bars & $-2.469 *$ & 0.983 & -2.510 & -0.021 & 0.027 & -0.780 & -0.040 & 0.049 & -0.820 \\
\hline Liquor stores & 0.686 & 0.396 & 1.730 & 0.011 & 0.011 & 1.020 & -0.003 & 0.020 & -0.150 \\
\hline Corner stores & 0.009 & 0.674 & 0.010 & -0.033 & 0.019 & -1.770 & $0.072 *$ & 0.034 & 2.120 \\
\hline Retail stores & -0.098 & 0.246 & -0.400 & 0.009 & 0.007 & 1.280 & $.037 * *$ & 0.012 & 3.040 \\
\hline Schools & 0.444 & 0.646 & 0.690 & $0.042 *$ & 0.018 & 2.360 & -0.008 & 0.032 & -0.240 \\
\hline Take outs & -0.252 & 0.687 & -0.370 & 0.006 & 0.019 & 0.340 & -0.052 & 0.034 & -1.500 \\
\hline Transit stops & 0.331 & 1.409 & 0.240 & -0.017 & 0.039 & -0.430 & 0.022 & 0.070 & 0.310 \\
\hline At-risk housing & 0.082 & 0.201 & 0.410 & -0.002 & 0.006 & -0.420 & 0.004 & 0.010 & 0.370 \\
\hline Parking lots & 0.154 & 0.180 & 0.860 & -0.006 & 0.005 & -1.130 & 0.002 & 0.009 & 0.260 \\
\hline \multicolumn{10}{|l|}{ Line of sight } \\
\hline $\begin{array}{l}\% \text { immovable } \\
\text { obstruct }\end{array}$ & $-0.698^{*}$ & 0.324 & -2.160 & $0.021 *$ & 0.009 & 2.310 & $-0.037^{*}$ & 0.016 & -2.270 \\
\hline$\%$ foliage obstruct & -0.303 & 0.196 & -1.540 & 0.000 & 0.005 & -0.090 & -0.002 & 0.010 & -0.170 \\
\hline Overlap & 1.891 & 5.021 & 0.380 & 0.056 & 0.139 & 0.400 & 0.182 & 0.251 & 0.720 \\
\hline \multicolumn{10}{|l|}{ Enforcement Activity } \\
\hline Detections & 0.128 & 0.306 & 0.420 & 0.002 & 0.008 & 0.250 & 0.026 & 0.015 & 1.690 \\
\hline Camera enforcement & -0.901 & 0.752 & -1.200 & 0.010 & 0.021 & 0.500 & $-0.088^{*}$ & 0.038 & -2.350 \\
\hline Unrelated arrests & -0.012 & 0.025 & -0.500 & 0.000 & 0.001 & -0.710 & -0.001 & 0.001 & -0.430 \\
\hline \multicolumn{10}{|l|}{ Camera style } \\
\hline Dome & -1.854 & 5.677 & -0.330 & 0.168 & 0.158 & 1.070 & -0.081 & 0.284 & -0.280 \\
\hline R-squared (adjusted) & \multicolumn{3}{|c|}{$0.206(0.079)$} & \multicolumn{3}{|c|}{$0.203(0.076)$} & \multicolumn{3}{|c|}{$0.203(0.075)$} \\
\hline Power (1- $\beta$ err prob) & \multicolumn{3}{|l|}{0.934} & \multicolumn{3}{|l|}{0.929} & \multicolumn{3}{|l|}{0.923} \\
\hline
\end{tabular}

$* p<0.05 ; * * p<0.01$

values. For example, the displacement analysis of the 55 viewsheds with negative $\Delta \mathrm{LQ}$ values for overall crime was conducted on the 40 catchment zones that resulted from the aforementioned merging process.

Table 5 provides a breakdown of the catchment zone $\Delta \mathrm{LQ}$ values across the six crime categories. For most crime categories, catchment areas exhibited positive $\Delta \mathrm{LQ}$ values, suggestive of displacement, more frequently than negative $\Delta \mathrm{LQ}$ values. The proportion of catchment zones with positive $\Delta \mathrm{LQ}$ values was $10 \%$ greater than those with negative $\Delta \mathrm{LQ}$ values in the overall crime ( 55 vs. $45 \%$ ), violent crime ( 57 vs. $42 \%$ ), and robbery (60 vs. $40 \%$ ) categories. This is in contrast to the viewsheds, in which violent crime was the only category where the proportion of viewsheds with positive $\Delta$ LQ values was $10 \%$ higher than those with negative $\Delta \mathrm{LQ}$ values (52 vs. $42 \%$ ). Auto theft was the only category for which the proportion of catchment zones exhibiting negative $\Delta$ LQ values, suggestive of diffusion of benefits, was $10 \%$ higher than those with positive $\Delta$ LQ values (57 vs. $42 \%)^{22}$

\footnotetext{
22 While Caplan et al. (2011) measured displacement on an aggregate level they did not calculate displacement measures for the individual viewsheds. Therefore, we are unable to compare the displacement findings with the earlier work of Caplan et al. (2011).
} 
Similar to the main analysis, we sought to test the influence of the independent variables on crime changes within the catchment zones to identify factors related to the occurrence of displacement and diffusion of benefits around CCTV cameras. The environmental features were measured within the catchment area. "Bars," for example, refers to the prevalence of bars (measured through a location quotient) in the catchment zone, not the viewshed. The remaining independent variable categories (line-of-sight, camera design and quantity, enforcement activity, and pre-installation crime levels) are camera specific and refer to the actual viewshed. Similar to the viewsheds, merged catchment zones differed slightly in how the "dome" variable was measured (see the "camera design" subsection of the "independent variables" section).

It should be noted that the low number of observations severely hampered the utility of the OLS models. For example, the overall crime model included 40 observations (catchment areas) and 16 covariates, translating to a rate of 2.5 events per predictor variable (EPV). Overall, the EPV of the catchment models ranged from 2.18 (violent crime and robbery) to 2.62 (auto theft and theft from auto). While previous simulation studies have demonstrated that models with EPVs as low as 5 are as statistically rigorous as models with as many as 16 EPV (Vittinghoff and McCulloch 2007) the EPV in our catchment models adds uncertainty to the results due to overfitting (Babyak 2004). The low EPV also presented issues regarding the model diagnostics, which we controlled for when possible. For example, we incorporated Heteroscedasticity-Consistent Standard Error estimators-specifically, MacKinnon and White's (1985) HC3 estimator-to control for observed heteroscedasticity in the robbery, auto theft, and theft from auto models. Other violations were unable to be corrected. Specifically, none of the dependent variables were normally distributed and "ladder of power" tests confirmed that no transformation method (e.g. squared, log, etc.) approximated a normal distribution. Thus, we present the catchment model findings as exploratory rather than confirmatory in nature.

Table 6 displays the results of the OLS models of the aggregate crime categories. Two covariates achieved statistical significance across the three models. Retail stores were associated with lower levels of violent crime in catchment zones while arrests unrelated to CCTV within viewsheds were associated with increased crime levels in the overall crime model. No covariates achieved statistical significance in the disaggregate crime category models.

\section{Discussion of Findings}

Statistically significant variables varied by model, suggesting the ideal context for CCTV may vary according to crime type. This was especially the case in respect to the environmental features. Five of the six models had at least one statistically significant environmental feature, with results in four models suggesting crime increases. Bars were the only environmental feature associated with decreased crime levels, achieving statistical significance in the violent crime and robbery models. While bars are commonly identified as criminogenic, the introduction of increased guardianship within and around these locations has shown to reduce incidents of crime and disorder (Felson 1995; Madensen and Eck 2008). While such guardianship has typically taken the form of human agents, such as place mangers, CCTV may have exerted similar influence in the surrounding areas of bars. Schools were associated with increased levels of auto theft while retail stores and corner stores were associated with increased levels of theft from auto. These findings regarding auto theft and theft from auto point to an obvious question; why was CCTV associated with 
Table 5 Number of viewsheds with negative $\Delta$ LQ values and resulting catchment zones

\begin{tabular}{lllll}
\hline Crime category & $\begin{array}{l}\text { Viewsheds with } \\
\text { neg. } \Delta \text { LQ }\end{array}$ & $\begin{array}{l}\text { Catchment } \\
\text { zones }\end{array}$ & $\begin{array}{l}\text { Catchment zones } \\
\text { with neg. } \Delta \text { LQ }\end{array}$ & $\begin{array}{l}\text { Catchment zones } \\
\text { with pos. } \Delta \text { LQ }\end{array}$ \\
\hline Overall crime & 55 & 40 & $18(45.00 \%)$ & $22(55.00 \%)$ \\
Violent crime & 50 & 35 & $15(42.85 \%)$ & $20(57.14 \%)$ \\
Robbery & 54 & 35 & $14(40.00 \%)$ & $21(60.00 \%)$ \\
Property crime & 58 & 41 & $19(46.34 \%)$ & $22(53.65 \%)$ \\
Auto theft & 54 & 42 & $24(57.14 \%)$ & $18(42.85 \%)$ \\
Theft from auto & 61 & 42 & $21(50.00 \%)$ & $21(50.00 \%)$ \\
\hline
\end{tabular}

increased crime levels when nearby schools, retail stores, and corner stores? A common argument is that CCTV operators may observe crime that may have otherwise gone unobserved (and unreported), which can cause an increase in reported crime whether or not actual crime levels changed (Winge and Knutsson 2003). However, since Newark's CCTV detections are mostly comprised of disorderly behavior and drug activity, with detections of Part 1 crime incidents a rarity (see Piza 2012: 53), this explanation does not apply in this case. Others have argued that CCTV can increase crime through more indirect means, such as by decreasing the vigilance of the public or reducing natural surveillance as fewer people use CCTV-covered areas due to privacy concerns (Gill and Turbin 1998). Perhaps characteristics of the aforementioned environs heighten such effects. While the necessary data to explore such hypotheses was unavailable to us, this is certainly an important issue worthy of future research.

Somewhat counterintuitive findings were observed in respect to the line-of-sight variables. Immovable visible obstructions were associated with increased levels of auto theft, suggesting that offenders may have taken advantage of opportunities to commit crimes in areas out of view of cameras (and camera operators) (Waples and Gill 2006). Conversely, immovable obstructions were associated with crime decreases in the violent crime, robbery, and theft from models. Perhaps the differing influence of obstructions can be explained by the crimes' differing natures. Particularly, auto theft takes longer to commit than violent crime, robbery, and theft from auto; since these crimes take place quickly, the ability to hide behind an immovable obstruction may not afford much benefit to this offender population. However, while this may explain the lack of significant theft from auto and robbery increases, it does not explain why decreased levels of these crimes were associated with immovable obstructions. Perhaps areas obstructed from view were not conducive to violent crime, robbery, or theft from auto, allowing operators to direct their attention towards specific places at higher risk of theft from auto. Whatever the reason, we caution against the interpretation that high levels of immovable obstructions heighten the effect of CCTV.

Findings relative to camera enforcement support the recent work of the Urban Institute (La Vigne et al. 2011), which suggests that CCTV effect depends largely on the level to which the cameras are integrated into the police function. "Camera enforcement" was associated with decreased levels of overall crime, violent crime, and theft from auto. The fact that camera enforcement was not significant across all of the models, however, speaks to the context-specific nature of CCTV. Research has shown CCTV to be most effective against incidents of property crime, specifically auto theft (Caplan et al. 2011; Farrington et al. 2007; Gill and Spriggs 2005; Welsh and Farrington 2009). It may be that formal surveillance via conspicuous camera presence may be enough to deter these crimes, with 
Table 6 OLS results for aggregate crime categories (catchment zones)

\begin{tabular}{|c|c|c|c|c|c|c|c|c|c|}
\hline \multirow[t]{2}{*}{ Variables } & \multicolumn{3}{|c|}{ Overall crime } & \multicolumn{3}{|c|}{ Violent crime } & \multicolumn{3}{|c|}{ Property crime } \\
\hline & $\beta$ & SE & $\mathrm{t}$ & $\beta$ & SE & $\mathrm{t}$ & $\beta$ & SE & $\mathrm{t}$ \\
\hline \multicolumn{10}{|l|}{ Environmental features } \\
\hline Bars & -0.163 & 0.130 & -1.250 & -0.018 & 0.309 & -0.060 & -0.114 & 0.291 & -0.390 \\
\hline Liquor stores & -0.105 & 0.093 & -1.120 & -0.151 & 0.155 & -0.980 & -0.212 & 0.237 & -0.890 \\
\hline Corner stores & 0.077 & 0.135 & 0.570 & -0.057 & 0.257 & -0.220 & 0.128 & 0.368 & 0.350 \\
\hline Retail stores & -0.007 & 0.066 & -0.100 & $-1.050^{*}$ & 0.415 & -2.530 & -0.078 & 0.136 & -0.580 \\
\hline Schools & -0.130 & 0.114 & -1.140 & 0.042 & 0.229 & 0.180 & -0.195 & 0.230 & -0.850 \\
\hline Take outs & -0.097 & 0.135 & -0.720 & -0.003 & 0.303 & -0.010 & -0.142 & 0.281 & -0.510 \\
\hline Transit stops & -0.054 & 0.278 & -0.190 & -0.145 & 0.382 & -0.380 & 0.282 & 0.571 & 0.490 \\
\hline At-risk housing & -0.040 & 0.131 & -0.310 & 0.139 & 0.302 & 0.460 & -0.072 & 0.281 & -0.260 \\
\hline Parking lots & 0.180 & 0.099 & 1.820 & 0.060 & 0.395 & 0.150 & 0.176 & 0.196 & 0.900 \\
\hline \multicolumn{10}{|l|}{ Line of sight } \\
\hline$\%$ immovable obstruct & 0.004 & 0.038 & 0.110 & 0.020 & 0.080 & 0.250 & 0.044 & 0.087 & 0.510 \\
\hline$\%$ foliage obstruct & 0.002 & 0.003 & 0.620 & 0.000 & 0.004 & 0.080 & 0.029 & 0.039 & 0.750 \\
\hline Overlap & -0.540 & 0.403 & -1.340 & 0.954 & 1.843 & 0.520 & 0.130 & 0.345 & 0.380 \\
\hline \multicolumn{10}{|l|}{ Enforcement activity } \\
\hline Detections & -0.058 & 0.056 & -1.040 & -0.191 & 0.130 & -1.470 & -0.017 & 0.145 & -0.120 \\
\hline Camera enforcement & 0.197 & 0.135 & 1.460 & 0.403 & 0.238 & 1.690 & -0.055 & 0.438 & -0.130 \\
\hline Unrelated arrests & $0.003 *$ & 0.002 & 2.240 & 0.004 & 0.012 & 0.320 & 0.002 & 0.004 & 0.440 \\
\hline \multicolumn{10}{|l|}{ Camera style } \\
\hline Dome & -0.003 & 0.666 & 0.000 & 1.260 & 1.655 & 0.760 & 0.022 & 1.447 & 0.010 \\
\hline R-squared (Adj.) & \multicolumn{3}{|c|}{$0.49(0.136)$} & \multicolumn{3}{|c|}{$0.529(0.110)$} & \multicolumn{3}{|c|}{$0.181(-0.365)$} \\
\hline Power (1- $\beta$ err prob) & \multicolumn{3}{|l|}{0.894} & \multicolumn{3}{|l|}{0.843} & \multicolumn{3}{|l|}{0.192} \\
\hline
\end{tabular}

$* p<0.05$

proactive enforcement being less crucial. Theft from auto offenders, on the other hand, may be more influenced by proactive enforcement since they typically operate on foot and are less likely to quickly flee the scene of a crime. In respect to violence, proactive enforcement has been shown to reduce the occurrence of such crime (Braga et al. 1999; MacDonald 2002; Sherman and Rogan 1995), explaining the negative correlation between violence and proactive camera enforcement. Conversely, robbery was not significantly influenced by camera enforcement, which is interesting given it is one of three crime types (along with murder and shootings) to comprise the "violent crime" category. This may be because robbers are more likely to offend in "risky" areas than other violent offenders since they are primarily motivated by monetary gain (Guerette et al. 2005). Piza and O'Hara's (2012) recent study suggests this may be especially true in Newark, with a drastic increase in police presence within a quarter-mile area reducing overall violence but having no effect on robbery.

\section{Conclusions}

This study sought to identify precise factors related to CCTV camera effect. However, like most research endeavors, the current study suffers from specific limitations that should be 
mentioned. It should be noted that the $\beta$ coefficients across the OLS models were small for all covariates. This is partly a byproduct of the dependent variable; the average $\Delta$ LQ values were well below 1 for all models (see Table 2). Such issues have also surfaced in previous research that quantified the micro-level effect of individual camera sites. For example, success measures of individual camera sites in Philadelphia ranged from a low of -0.0042 to a high of 0.0023 (Ratcliffe et al. 2009: 760-764). When such small values are utilized as dependent variables the resulting coefficients of model covariates are likely to be similarly small. However, the small coefficients may also suggest that the effects of the covariates on crime levels were somewhat modest. Indeed, a small proportion of the covariates achieved statistical significance. Furthermore, each model generated relatively low $\mathrm{r}^{2}$ values, meaning most of the variance in the dependent variables went unexplained. Thus, we advocate for replication of this study in other jurisdictions to further explore, and improve upon, the identification of the determinant factors of CCTV effect.

Limitations were also present in other aspects of the methodology. For one, viewshed creation occurred during the months of April through September, which may have somewhat compromised the digitizing of visible obstructions. While researchers accurately captured the presence of foliage obstructions during these warm-weather months, in certain instances we were unable to determine if any immovable obstructions (e.g. a bus shelter or telephone pole) were blocked from view by the foliage. This may have resulted in immovable obstructions being underrepresented in our models. We were also unable to control for changes in the land use of facility types that may have occurred during the intervention period, a problem commonly faced in environmental criminology studies (De Souza and Miller 2012). In addition, the environmental features included in this study represent but a sample of those that may influence CCTV effect. Indeed, other researchers have faced similar challenges in selecting which variables to include in tests of land use influence on crime (see Bernasco and Block 2011). The covariates additionally did not include a category that controlled for human-related aspects of CCTV, such as operator decision making, that may influence detection and enforcement levels around certain cameras. Despite the likely omission of important variables from our models, we decided to only utilize the readily available covariates in order to maintain statistical power and protect against model overfitting. Similarly, our analysis of displacement was severely hampered by the very small number of catchment areas. We encourage the inclusion of additional covariates and a rigorous test of displacement in future research when a larger "N" is available.

Acknowledgments This research was supported by the National Institute of Justice, Grant No. 2010-IJCX-0026. We express our gratitude to Sergeant Marvin Carpenter and the surveillance operators of the Newark Police Department for their generous support. We also wish to acknowledge the research assistants that worked on this project for their diligence and dedication: Kayla Crager, Andrew Gilchrist, and Christopher Perez. Finally, we thank a number of our colleagues who gave us valuable advice regarding the research methodology and statistical analysis of this project: Robert Apel, Anthony Braga, Elizabeth Griffiths, and Joel Miller.

\section{Appendix}

The reader may be interested in how the $\triangle \mathrm{LQ}$ distribution of the current study compares to that of Caplan et al. (2011). However, the differing scope of these works makes comparisons somewhat limited. Specifically, auto theft and theft from auto are the only two crime types included in both studies. In addition, Caplan et al. (2011) analyzed 73 of 
Newark's 146 cameras that were installed at the time. Therefore, we are restricted to discussing the auto theft and theft from auto findings for the cameras included in both studies.

Thirty-four viewsheds experienced reduced levels of auto theft in the Caplan et al. study, with 35 auto theft reductions being observed in the current study. Differences were more pronounced in respect to theft from auto; 41 viewsheds exhibited reduced crime levels in the Caplan et al. study while only 35 exhibited a reduction in the current study. These differences are likely due to the differing methodologies of the two studies, specifically in regards to the LQ formulas and the units of analysis. LQs employed by Caplan et al. controlled for city-wide geography and crime totals while precinct-level data was used in the current study. In addition, while the current study excluded incidents in the surrounding catchment zone from the LQ formula, Caplan et al. included such incidents. Finally, the different approaches to viewshed creation resulted in units of analysis significantly different in size, as confirmed via an independent samples $t$ test $(p<0.01)$. The average area of viewsheds in the Caplan et al. study was more than twice the size of our viewsheds $\left(268,635\right.$ vs. $\left.112,615 \mathrm{ft}^{2}\right)$. These methodological differences mean that measures of success are not uniform across studies. Therefore, comparison of findings may be more of an "apples-to-oranges" situation than one may expect given the identical study setting.

\section{References}

Armitage R (2002) To CCTV or not? A review of current research into the effectiveness of CCTV systems in reducing crime. National Association for the Care and Resettlement of Offenders, London

Babyak M (2004) What you see may not be what you get: a brief, nontechnical introduction to overfitting in regression-type models. Psychosom Med 66:411-421

Bernasco W, Block R (2011) Robberies in Chicago: a block-level analysis of the influence of crime generators, crime attractors, and offender anchor points. J Res Crime Deling 48(1):33-57

Block R, Block C (1999) The Bronx and Chicago: street robbery in the environs of rapid transit stations. In: Goldsmith V, McGuire PG, Mollenkopf JH, Ross TA (eds) Analyzing crime patterns: frontiers of practice. Sage, Thousand Oaks, CA

Bowers K, Johnson J (2003) Measuring the geographical displacement and diffusion of benefit effects of crime prevention activity. J Quant Criminol 19(3):275-301

Braga A, Weisburd D, Waring E, Mazerolle L, Spelman W, Gajewski F (1999) Problem-oriented policing in violent crime places: a randomized controlled experiment. Criminology 37(3):541-580

Braga A, Hureau D, Papachristos A (2011) The relevance of micro places to citywide robbery trends: a longitudinal analysis of robbery incidents at street corners and block faces in Boston. J Res Crime Delinq 48(1):7-32

Brantingham PJ, Brantingham PL (1981) Environmental criminology. Sage, Beverly Hills, CA

Brantingham PL, Brantingham PJ (1993) Nodes, paths and edges: consideration on the complexity of crime and the physical environment. J Environ Psychol 13:3-28

Brantingham PJ, Brantingham PL (1995) Criminality of place: crime generators and crime attractors. Eur J Crim Policy Res 3(3):1-26

Brantingham PL, Brantingham PJ (1998) Mapping crime for analytic purposes: location quotients, counts and rates. In: Weisburd D, McEwen T (eds) Crime mapping and crime prevention. Crime prevention studies, vol 8, pp 263-288

Britt C, Weisburd D (2010) Statistical power. In: Piquero A, Weisburd D (eds) Handbook of quantitative criminology. Springer, New York, NY

Brown B (1995) CCTV in town centres: three case studies. Crime detection and prevention series, paper 68. Home Office, London

Cameron A, Kolodinski E, May H, Williams N (2008) Measuring the effects of video surveillance on crime in Los Angeles. Report prepared for the California Research Bureau. USC School of Policy, Planning, and Development 
Caplan J (2011) Mapping the spatial influence of crime correlates: a comparison of operationalization schemes and implications for crime analysis and criminal justice practice. Cityscape 13(3):57-83

Caplan J, Kennedy L, Petrossian G (2011) Police-monitored cameras in Newark, NJ: a quasi-experimental test of crime deterrence. J Exp Criminol 7(3):255-274

Chainey S (2000) Optimizing closed-circuit television use. In: La Vigne N, Wartell J (eds) Crime mapping case studies: successes in the field, vol 2. Police Executive Research Forum, Washington, DC

Chakravart I, Laha R, Roy J (1967) Handbook of methods of applied statistics, vol 1. Wiley, Hoboken, NJ

Clarke R, Weisburd D (1994) Diffusion of crime control benefits. In: Clarke R (ed) Crime prevention studies, vol 2. Criminal Justice Press, Monsey, NY, pp 165-183

Cook T, Campbell D (1979) Quasi-experimentation: design and analysis issues for field settings. Rand McNally, Chicago, IL

De Souza E, Miller J (2012) Homicide in the Brazilian favela: does opportunity make the killer? Br J Criminol 52:786-807

Ditton J, Short E (1999) Yes it works. No it doesn't: comparing the effects of open-street CCTV in two adjacent Scottish town centres. In: Tilley N, Painter K (eds) Surveillance of public space: CCTV, street lighting and crime prevention. Crime prevention studies, vol 10. Criminal Justice Press, Monsey, NY

Eck J (1993) The threat of crime displacement. Crim Justice Abstr 253:527-546

Eck J (1994) Drug markets and drug places: a case-controlled study of spatial structure of illicit dealing. Unpublished Ph.D. Dissertation, University of Maryland, College Park

Eck J (2002) Preventing crime at places. In: Sherman L, Farrington D, Welsh B, Mackenzie D (eds) Evidence-based crime prevention. Routledge, New York, NY, pp 241-294

Eck J, Weisburd D (eds) (1995) Crime and place. Crime prevention studies, vol 4. Criminal Justice Press, Monsey, NY

Farrington D, Gill M, Waples S, Argomaniz J (2007) The effects of closed-circuit television on crime: metaanalysis of an English national quasi-experimental multi-site evaluation. J Exp Criminol 3:21-28

Faul F, Erdfelder E, Buchner A, Lang A (2009) Statistical power analyses using G*Power 3.1: tests for correlation and regression analyses. Behav Res Methods 41(4):1149-1160

Felson M (1995) Those who discourage crime. In: Eck J, Weisburd D (eds) Crime and place: crime prevention studies, vol 4. Police Executive Research Forum, Washington, DC

Felson M (2002) Crime and everyday life, 3rd edn. Sage, Thousand Oaks, CA

Freundschuh S, Egenhofer M (1997) Human conceptions of spaces: implications for GIS. Trans GIS 2(4):361-375

Gill M, Spriggs A (2005) Assessing the impact of CCTV. Home Office Research Study No. 292, London

Gill M, Turbin V (1998) CCTV and shop theft: towards a realistic evaluation. In: Norris C, Moran J, Armstrong G (eds) Surveillance, closed circuit television, and social control. Ashgate, Brookfield, VT

Gill M, Spriggs A, Allen J, Hemming M, Jessiman P, Kara D (2005) Control room operation: findings form control room observations. Home Office, London

Gill M, Rose A, Collins K, Hemming M (2006) Redeployable CCTV and drug-related crime: a case of implementation failure. Drugs Educ Prev Policy 13(5):451-460

Groff E, La Vigne N (2001) Mapping an opportunity surface of residential burglary. J Res Crime Delinq $38: 257-278$

Guerette R, Steinus V, McGloin J (2005) Understanding offending specialization and versatility: a reapplication of the rational choice perspective. J Crim Justice 33(1):77-87

Hamilton L (2013) Statistics with STATA. Updated for version 12. Cengage Brooks/Cole, Boston, MA

Ittelson W (1973) Environment perception and contemporary perceptual theory. In: Ittelson W (ed) Environment and cognition. Seminar, New York, pp 1-19

Johnson S, Bowers K, Birks D, Pease K (2009) Predictive mapping of crime by ProMap: accuracy, units of analysis, and the environmental backcloth. In: Weisburd D, Bernasco W, Bruinsma G (eds) Putting crime in its place: units of analysis in geographic criminology. Springer, New York

Kennedy L, Caplan J, Piza E (2011) Risk clusters, hotspots, and spatial intelligence: risk terrain modeling as an algorithm for police resource allocation strategies. J Quant Criminol 27(3):339-362

Keval H, Sasse A (2010) "Not the usual suspects": a study of factors reducing the effectiveness of CCTV. Secur J 23(2):134-154

King J, Mulligan D, Raphael S (2008) CITRIS Report: the San Francisco community safety camera program. An evaluation of the effectiveness of San Francisco's community safety cameras. Research in the Interest of Society. Center for Information Technology Research in the Interest of Society, University of California, Berkeley

La Vigne N, Lowry S (2011) Evaluation of camera use to prevent crime in commuter parking lots: a randomized controlled trial. Urban Institute, Justice Policy Center, Washington, DC 
La Vigne N, Lowry S, Markman J, Dwyer A (2011) Evaluating the use of public surveillance cameras for crime control and prevention. US Department of Justice, Office of Community Oriented Policing Services. Urban Institute, Justice Policy Center, Washington, DC

Lynch K (1960) Image of the city. MIT Press, Cambridge, MA

MacDonald J (2002) The effectiveness of community policing in reducing urban violence. Crime Delinq 48:592-618

MacKinnon J, White H (1985) Some heteroscedasticity consistent covariance estimators with improved finite sample properties. J Econ 29:53-57

Madensen T, Eck J (2008) Violence in bars: exploring the impact of place manager decision-making. Crime Prev Community Saf 10(2):111-125

Maxfield M, Babbie E (2001) Research methods for criminal justice and criminology, 3rd edn. Wadsworth/ Thompson Learning, Belmont, CA

Mazerolle L, Hurley D, Chamlin M (2002) Social behavior in public space: an analysis of behavioral adaptations to CCTV. Secur J 15(3):59-75

McClendon M (1994) Multiple regression and causal analysis. F. E. Peacock Publishers, Itasca, IL

Myers P (2002) The management of identity in bodegas: stigma and microeconomics in Brooklyn. J Ethn Subst Abuse 1(3):75-93

Norris C, Armstrong G (1999) CCTV and the social structuring of surveillance. In: Tilley N, Painter K (eds) Surveillance of public space: CCTV, street lighting and crime prevention. Crime prevention studies, vol 10. Criminal Justice Press, Monsey, NY

Norris C, McCahill M (2006) CCTV: beyond penal modernism? Br J Criminol 46:97-118

Oberwittler D, Wikström P (2009) Why smaller is better: advancing the study of the role of behavioral contexts in crime causation. In: Weisburd D, Bernasco W, Bruinsma G (eds) Putting crime in its place: units of analysis in geographic criminology. Springer, New York

Phillips C (1999) A review of CCTV evaluations: crime reduction effects and attitudes towards its use. In: Tilley N, Painter K (eds) Surveillance of public space: CCTV, Street lighting and crime prevention. Crime prevention studies, vol 10. Criminal Justice Press, Monsey, NY

Piza E (2012) Identifying the ideal context for CCTV camera placement: an analysis of micro-level features. Doctoral Dissertation submitted to the Graduate School-Newark, Rutgers, The State University of New Jersey

Piza E, O’Hara B (2012) Saturation foot-patrol in a high-violence area: a quasi-experimental evaluation. Justice Q. Advance online publication. doi:10.1080/07418825.2012.668923

Piza E, Caplan J, Kennedy L (2012) Is the punishment more certain? An analysis of CCTV detections and enforcement. Justice Q. Advance online publication. doi:10.1080/07418825.2012.723034

Ratcliffe J (2006) Video surveillance of public places. Problem-oriented guides for police. Response guide series. Guide No. 4. US Department of Justice Office of Community Oriented Policing Services. Center for Problem-Oriented Policing

Ratcliffe J (2010) Crime mapping: spatial and temporal challenges. In: Weisburd D, Piquero A (eds) Handbook of quantitative criminology. Springer, New York, NY

Ratcliffe J (2012) The spatial extent of criminogenic places: a changepoint regression of violence around bars. Geogr Anal 44:302-330

Ratcliffe J, Taniguchi T, Taylor R (2009) The crime reduction effects of public CCTV cameras: a multimethod spatial approach. Justice Q 26(4):746-770

Roncek D (2000) Schools and crime. In: Goldsmith V, McGuire P, Mollenkopf J, Ross A (eds) Analyzing crime patterns: frontiers of practice. Sage, Thousand Oaks, CA, pp 153-165

Sarno C, Hough M, Bulos M (1999) Developing a picture of CCTV in Southwark town centres: final report. Criminal Policy Research Unit, South Bank University, London

Scott M, Dedel K (2006) Assaults in and around bars, 2nd edn. Problem-Oriented Guides for Police. Problem-specific Guides Series. Guide No. 4. US Department of Justice, Office of Community Oriented Policing Services, Center for Problem-Oriented Policing, Washington, DC

Sherman L (1990) Police crackdowns: initial and residual deterrence. In: Tonry M, Morris N (eds) Crime and justice: a review of research, vol 12. University of Chicago Press, Chicago, pp 1-48

Sherman L, Rogan D (1995) Effects of gun seizures on gun violence: 'hot spots' patrol in Kansas City. Justice Q 12:673-694

Sivarajasingam V, Shepherd J, Matthews K (2003) Effect of urban closed circuit television on assault injury and violence detection. Inj Prev 9:312-316

Smith G (2004) Behind the scenes: examining constructions of deviance and informal practices among CCTV control room operators in the UK. Surveill Soc 2(2/3):376-395

Smith M, Clarke R (2000) Crime and public transport. Crime Justice 27:169-233 
Squires P (2000) CCTV and crime reduction in Crawley. Health and Social Police Research Center, Brighton

Stucky T, Ottensmann J (2009) Land use and violent crime. Criminology 47(4):1223-1264

Taylor R, Harrell A (1996) Physical environment and crime. National Institute of Justice, Washington, DC Tukey J (1977) Exploratory data analysis. Addison-Wesley, Reading, MA

UCLA (2007) Chapter 2: regression diagnostics. In: Stata web books: regression with Stata. University of California Los Angeles: Academic Technology Services, Statistical Consulting Group

US Census Bureau (2011). Quick facts from US Census Bureau. Retrieved on 12 March 2011 from http://quickfacts.census.gov

Vittinghoff E, McCulloch C (2007) Relaxing the rule of ten events per variable in logistic and cox regression. Am J Epidemiol 165(6):710-718

Waples S, Gill M (2006) The effectiveness of redeployable CCTV. Crime Prev Community Saf 8:1-16

Weisburd D, Green L (1995) Measuring intermediate spatial displacement: methodological issues and problems. In: Eck J, Weisburd D (eds) Crime and place: crime prevention studies, vol 4. Criminal Justice Press, Monsey, NY, pp 349-361

Weisburd D, Morris N, Ready J (2008) Risk-focused policing at places: an experimental evaluation. Justice Q 25(1):163-200

Welsh B, Farrington D (2002) Crime prevention effects of closed circuit television: a systematic review. Home Office, London (Research Study No. 25)

Welsh B, Farrington D (2007) Closed-circuit television surveillance and crime prevention: a systematic review. National Council for Crime Prevention, Stockholm

Welsh B, Farrington D (2009) Public area CCTV and crime prevention: an updated systematic review and meta-analysis. Justice Q 26(4):716-745

Winge S, Knutsson J (2003) An evaluation of the CCTV scheme at Oslo central railway station. Crime Prev Community Saf Int J 5(3):49-59

Zanin N, Shane J, Clarke R (2004) Reducing drug dealing in private apartment complexes in Newark, NJ. A final report to the US Department of Justice, Office of Community Oriented Policing Services on the Field Applications of the Problem-Oriented Guides for Police Project 